\title{
PORE-THROAT STRUCTURE AND FRACTAL CHARACTERISTICS OF SHIHEZI FORMATION TIGHT GAS SANDSTONE IN THE ORDOS BASIN, CHINA
}

 \\ WEI JI,\| JINGKUN JIA, ${ }^{\ddagger}$ XIANGLU TANG,${ }^{\ddagger}$, SHAOHUA ZHANG, ${ }^{*, \dagger}$ \\ JIANWEN GAO*,† and BIN LUO ${ }^{*, \dagger}$ \\ *State Key Laboratory of Continental Dynamics of Ministry of Geology \\ Northwest University, Xi'an 710069, P. R. China \\ ${ }^{\dagger}$ Department of Geology, Northwest University, Xi'an 710069, P. R. China \\ ${ }^{\ddagger}$ State Key Laboratory of Petroleum Resources and Prospecting \\ China University of Petroleum, Beijing 102249, P. R. China \\ $\S$ Unconventional Natural Gas Institute, China University \\ of Petroleum, Beijing 102249, P. R. China \\ ISchool of Earth Sciences, The Ohio State University \\ Columbus, OH 43210, USA \\ ${ }$ Changqing Division of China Petroleum Group Logging \\ Co., Ltd., Xi'an 710201, P. R. China \\ ** chenlei19880804@163.com \\ †txiong.291@osu.edu
}

Received November 20, 2017

Accepted January 4, 2018

Published February 23, 2018

\begin{abstract}
In order to better understand the impact of fractal features of pore-throat structures on effective physical properties of tight gas sandstones, this paper carried out constant-rate mercury
\end{abstract}

\footnotetext{
$\$ \ddagger$ Corresponding authors.

This is an Open Access article published by World Scientific Publishing Company. It is distributed under the terms of the Creative Commons Attribution 4.0 (CC-BY) License. Further distribution of this work is permitted, provided the original work is properly cited.
} 
H. Huang et al.

\begin{abstract}
injection tests, gas-water permeability analyses, helium-based porosity and nitrogen pulse decay permeability measurements, and SEM and casting thin-section analyses on 20 sandstone samples of the Shihezi Formation from 16 wells of the Sulige Gas Field in the Ordos Basin, China. The fractal dimensions of pores corresponding to two pore radius ranges, namely fractal dimensions $D_{p 2}$ and $D_{p 3}$, and those of throats also corresponding to two throat radius ranges, namely fractal dimensions $D_{t 1}$ and $D_{t 2}$, were then calculated using the constant-rate mercury injection data. Fractal dimensions $D_{p 2}$ and $D_{p 3}$ are negatively correlated with the average pore radius and pore volume as well as quartz content, and they are positively related to contents of clay minerals and lithic fragments. Compared with pore fractal dimensions, throat fractal dimensions have lower correlations with throat structural parameters, and show vague relations with mineral compositions. Although the effects imposed by mineral compositions upon throat structures are similar to those upon pore structures, the flake-like and curved shapes of throats result in irregularity of fractal dimensions. Tight gas sandstones, with smaller fractal dimensions $D_{p 2}$ and $D_{p 3}$, have larger effective porosity, indicating that more gas volumes can be replaced by liquids. As for tight gas sandstones with lower fractal dimensions $D_{p 3}$ and $D_{t 2}$, the effective gas permeability is relatively high. In such cases, gas can flow more easily through the reservoir.
\end{abstract}

Keywords: Tight Gas; Pore-Throat Structure; Constant-Rate Mercury Injection Test; Fractal Dimension; Shihezi Formation; Ordos Basin.

\section{INTRODUCTION}

In China, tight gas sandstone reservoirs refer to the sandstones with gas permeability below $1 \times 10^{-3} \mu \mathrm{m}^{3}$ (about $1 \mathrm{mD}$ )! 1 They are extensively distributed in the Sulige Gas Field, Ordos Basin, with a gas-bearing area of $4 \times 10^{4} \mathrm{~km}^{2}$. Sulige Gas Field is the largest gas field ever discovered in China, with main pay zones of Permian Shihezi Formation and Shanxi Formation ${ }^{2}$ Unlike conventional sandstone gas reservoirs, tight gas sandstones are characterized by their low-ultra-low permeability. Therefore, it is necessary to introduce large-scale fracturing stimulation or specific recovery technologies so as to achieve economic production. $\stackrel{113}{\text { Explo- }}$ ration and development in such reservoirs are hindered by extreme heterogeneity owing to the fine pores and complex pore characteristics including size, shape, location and connectivity of pores and throats. 4 As one of the most primary factors controlling the exploitation of tight gas sandstones, the pore-throat structure of fine pores has been extensively studied. It is generally believed that the pore-throat structure directly impacts the fluid flow through the reservoir and thus further affects the hydrocarbon recovery. Smooth pore-throat surfaces favor the gas flow, while tortuous pore-throat

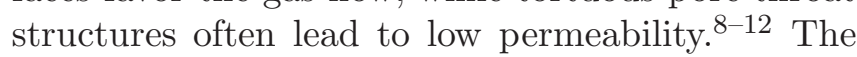
structure characteristic of pores and throats is also to some extent capable of influencing the gas charging process, which imposes direct effects on the gas content in the reservoir. Hence, it is of great significance to study the pore-throat structure to better understand gas flow and accumulation in tight sands.

Frequently used methods to characterize the pore-throat structure of tight gas reservoirs include direct observation (e.g. the electron microscope, scanning electron microscope and CT scanner $13 \frac{18}{18}$ and indirect measurement (e.g. mercury injection, gas adsorption and nuclear magnetic resonance)!14|19]23 Mercury injection test is a well-proved effective approach to characterize the pore-throat structure of sandstones, 11112 24 and constant-rate mercury injection data can distinguish pores from throats ${ }^{7,25}$ and reflect their respective fractal features ${ }^{[7}$ However, studies regarding individual effects of pore and throat fractal features on gas flow in tight gas sands are rare.

Fractal geometry, which is often used to study irregular but self-similar shapes in nature, is a powerful tool to quantitatively characterize complexity. The microscopic pore-throat structure of tight sandstone gas reservoirs is just such a complex system with fractal features.$^{7}$ According to the complexity of pore-throat structure of tight sandstone gas reservoir in the three-dimensional space, the structure fractal dimension should be between 2 and 3. Therefore, fractal characteristics of the spatial distributions of pores and throats can be respectively described based on distinction of them. 
Further, physical property parameters, mineral compositions, and pore-throat structure parameters can be combined to discuss the physical meaning indicated by the pore-throat radius distribution range with fractal characteristics.

This paper analyzed the fractal characteristics of the pore-throat structure of the tight gas sandstone in the Permian Shihezi Formation, the Ordos Basin, China. Fractal dimensions of pores and throats were respectively calculated, on the basis of constant-rate mercury injection test. Correlations between the fractal dimension, mineral composition and porethroat structure parameter were analyzed. This paper also discussed the effects of fractal dimensions of the pore-throat structure on the gas flow capacity of the formation. Findings of this research can help better understand the pore-structure of tight gas sandstones and evaluate the gas-bearing capacity of the Permian Shihezi Formation in the Ordos Basin.

\section{SAMPLES AND EXPERIMENTAL METHODOLOGY}

The Ordos Basin in the central and western China is located in the western margin of the North China block, where there are six first-order tectonic units, namely the Yimeng Uplift, Jingxi Folding Belt, Tianhuan Depression, Yishan Slope, Western Edge Thrust Belt and Weibei Uplift. Archaean and lower Proterozoic crystalline rocks formed the basin basement 23126] 28 Permian Shihezi Formation is one of the main pay zones of the Sulige Gas Field, the largest gas field in the basin. It consists of a series of sediments of the deltaic plain subfacies, among which the channel sand body is the target for gas exploration and exploitation $[2 \mid 27$ Twenty tight sandstone core samples were collected from 16 wells in the Sulige Gas Field. These 16 wells are in the eastern and western Sulige Gas Field, with the target in the upper Paleozoic (Fig. 1), while the southern Sulige Gas Field targets at the lower Paleozoic.

The collected 20 core samples were further processed for casting thin section and SEM analyses. Pore-throat structures and mineral compositions were observed and identified in the casting thin sections using the LEICADMRXHC polarized light microscope manufactured by LEICA based in Germany. Besides, insights into micro features of the core samples were acquired, using the FEI Quanta 400 FEG scanning electron microscope manufactured by FEI Company.
Moreover, cylinders with a diameter of $2.5 \mathrm{~cm}$ and flattened ends were made from the core samples. Helium-based porosity, nitrogen pulse decay permeability and gas-water relative permeability measurements were then carried out.

In the helium porosity measurement, samples were dried and cooled down, before being put in the core holder of the helium-based porosity testing apparatus. After opening the helium control valve and initiating the test, equilibrium pressures with two different initial pressures, namely $4 \mathrm{MPa}$ and $8 \mathrm{MPa}$, were respectively recorded. Data were acquired at intervals of $1 \mathrm{~s}$. Porosity was then calculated according to the Boyle's law, and each sample was repeatedly tested for 3 times for an average. 29 The KXD-III helium-based porosity testing apparatus of the State Key Laboratory of Petroleum Resources and Prospecting, China University of Petroleum (Beijing), China, made by the Jiangsu Hua'an Scientific Research Devices Co., Ltd., was used for the test, and the measurement complied with GB/T 21650.2-2008 (China's national testing standard).

Nitrogen pulse decay permeability test was then carried out on samples after the porosity measurement. The diameter, length and helium-based porosity data were input into the testing software. Cylindrical core samples were fixed in the core holder, to which confining pressures were then applied via a manual pressurizer. Then a nitrogen pressure pulse was exerted on the upper end of the sample, and the correlation between time and pressure difference between the upper and lower ends of the sample was used to calculate the permeability. Data were acquired at intervals of $30 \mathrm{~s}$. The test was conducted using the CP-200 pulse decay permeability testing apparatus of the State Key Laboratory of Petroleum Resources and Prospecting, China University of Petroleum (Beijing), manufactured by the Beijing Yongruida Technology Co., Ltd., and followed SY/T 6370/1998 (China's national testing standard).

The gas-water relative permeability measurement was carried out after the porosity and permeability measurement, using the unsteady state method based on the Buckley-Leverett oildisplacing theory, in which the gas and water saturations are defined as functions of time and distance (to the injection end). Samples were saturated with water and placed into the rubber case in the holder. Confining pressures were then applied to rubber case, and the testing apparatus 


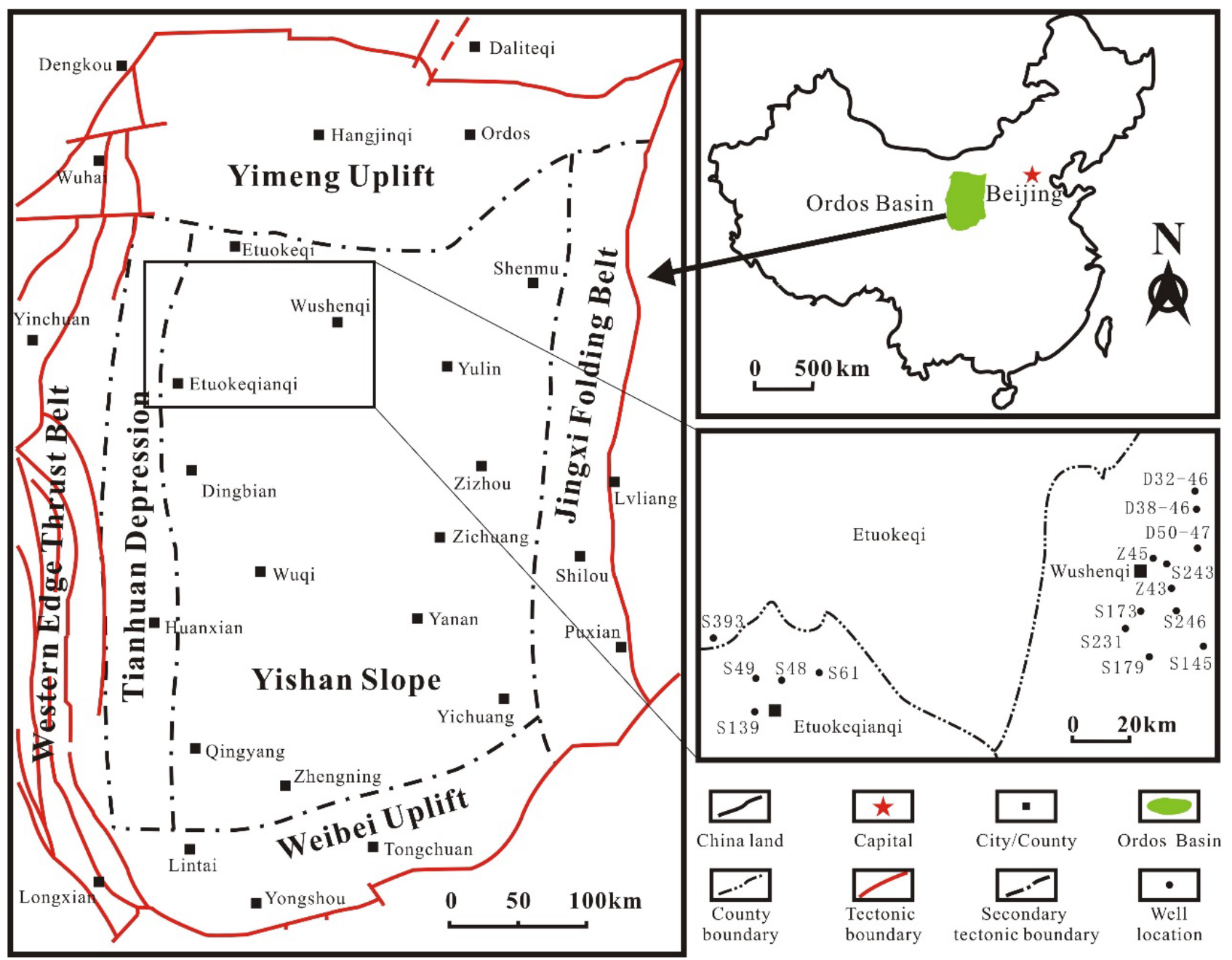

Fig. 1 Location of the Ordos Basin and sampling spots.

was capable of automatically maintaining the displacement pressure and confining pressure during the test. The DQT-2 multi-functional core flooding apparatus of the State Key Laboratory of Petroleum Resources and Prospecting, China University of Petroleum (Beijing), manufactured by the Hai'an County Petroleum Research Devices Co., Ltd., was used in the test, and the measurement was carried out, complying to SY/T 5345-2007 (China's national testing standard).

Finally, segments with length of $0.5 \mathrm{~cm}$ were cut from the 20 core cylinders after the gas-water relative permeability test, and dried at $100^{\circ} \mathrm{C}$ for over $24 \mathrm{~h}$. Dry segments were then immersed into mercury, while mercury was injected into the sample at a constant extremely low rate $(0.00005 \mathrm{~mL} / \mathrm{min})$. It was assumed that the contact angle and the interfacial tension were constant during the mercury injection. The injection pressure rose when mercury enters the throat, and dropped instantly once it exceeded the capillary pressure at the throat. Then mercury penetrated into the next pore through overcoming throat restriction. After the pore was filled, another rising-dropping cycle of injection pressures began. Each test was ended when the injection pressure reached $6.2055 \mathrm{MPa}$, which corresponded to a throat radius of $0.12 \mu \mathrm{m}$ according to Washburn's equation $30-34$ The ASPE730 Automated System for Pore Examination of the Percolation Dynamics Research Institute, Chinese Academy of Sciences, Langfang, China, made by Coretest Systems, was adopted. Tests were performed following SY/T 5346-2005 (China's national testing standard).

\section{RESULTS}

\subsection{Minerals}

Detailed mineral compositions based on the thin section analysis are shown in Table1, Quartz family 
Table 1 Mineral Compositions of Core Samples from the Shihezi Formation.

\begin{tabular}{|c|c|c|c|c|c|c|c|c|}
\hline \multirow[t]{2}{*}{ Sample ID } & \multirow[t]{2}{*}{ Depth $[\mathbf{m}]$} & \multicolumn{7}{|c|}{ Mineral Compositions [\%] } \\
\hline & & Quartz & Chert & Feldspar & $\begin{array}{c}\text { Igneous } \\
\text { Lithics }\end{array}$ & $\begin{array}{c}\text { Metamorphics } \\
\text { Lithics }\end{array}$ & $\begin{array}{l}\text { Other } \\
\text { Lithics }\end{array}$ & $\begin{array}{l}\text { Interstitial } \\
\text { Substance }\end{array}$ \\
\hline D32-46 & 2989.28 & 64 & 2 & 1 & 3 & 13 & 3 & 14 \\
\hline D38-46 & 3026.23 & 51 & 2 & 0 & 5 & 23 & 7 & 12 \\
\hline D50-47-1 & 3106.30 & 56 & 1 & 1 & 4 & 22 & 6 & 10 \\
\hline D50-47-2 & 3108.17 & 69 & 3 & 0 & 2 & 15 & 2 & 9 \\
\hline S139 & 3642.88 & 75 & 0 & 1 & 2 & 11 & 3 & 8 \\
\hline $\mathrm{S} 145$ & 3134.60 & 74 & 2 & 0 & 1 & 5 & 5 & 13 \\
\hline S173 & 3125.96 & 73 & 2 & 0 & 1 & 6 & 7 & 11 \\
\hline S179 & 3143.15 & 43 & 3 & 0 & 8 & 21 & 7 & 18 \\
\hline $\mathrm{S} 231$ & 3143.00 & 73 & 2 & 1 & 8 & 5 & 0 & 11 \\
\hline $\mathrm{S} 243$ & 3047.56 & 58 & 3 & 0 & 5 & 22 & 3 & 9 \\
\hline S246-1 & 3027.50 & 71 & 4 & 0 & 3 & 8 & 5 & 9 \\
\hline S246-2 & 3049.00 & 75 & 3 & 0 & 2 & 7 & 0 & 13 \\
\hline S393 & 3666.42 & 70 & 1 & 0 & 6 & 10 & 6 & 7 \\
\hline $\mathrm{S} 48$ & 3625.06 & 78 & 2 & 1 & 3 & 2 & 3 & 11 \\
\hline S49 & 3635.68 & 62 & 2 & 2 & 1 & 15.5 & 4 & 13.5 \\
\hline S61 & 3610.44 & 72 & 1 & 1 & 3 & 9 & 6 & 8 \\
\hline $\mathrm{Z} 43$ & 3080.74 & 56 & 3 & 0 & 3 & 23 & 0 & 15 \\
\hline Z45-1 & 3131.14 & 53 & 1 & 2 & 6 & 21 & 6 & 11 \\
\hline Z45-2 & 3132.50 & 64 & 2 & 0 & 4 & 16 & 4 & 10 \\
\hline Z45-3 & 3137.23 & 65 & 2 & 0 & 5 & 18 & 2 & 8 \\
\hline
\end{tabular}

minerals, accounting for $46 \%-80 \%$ of the total rock with an average content of $67.15 \%$, include quartz $(43 \%-78 \%)$ and chert $(0-4 \%)$. Feldspar is hardly found in all samples (0-2\%). Lithic fragments mainly come from igneous $(1 \%-8 \%)$, and in more cases, metamorphic $(2 \%-23 \%)$ rocks. The total lithic fragment content ranges from $8 \%$ to $36 \%$, averaging $21.33 \%$. The interstitial filling, primarily including silica cements, clay and ferrocalcite, accounts for $7 \%-18 \%$, with an average of $11.03 \%$.

\subsection{Gas-Water Relative Permeability}

The 20 sandstone samples from the Shihezi Formation were first implemented with the nitrogen pulse decay permeability test before the gaswater relative permeability measurement. Results show that seven samples present gas permeability exceeding the value in the definition of tight sandstones, ${ }^{1}$ although the Shihezi Formation of the Sulige Gas Field is commonly believed as the tight gas sandstone. On the basis of comparison among different samples of the Shihezi Formation and previous long-term understanding of this formation, this paper still carried out tests and analyses for all samples and generally classified them as tight gas sandstones. In the gas-water relative permeability test (Fig. 2), the effective porosity, $\phi_{e}$, refers to the space that is truly gas-water displaceable in the sample. It can be calculated by subtracting the bound water volume and the residual gas volume from the total pore space volume, as illustrated by Eq. (11):

$$
\phi_{e}=\left[1-0.01 \cdot\left(S_{\mathrm{Iws}}+S_{\mathrm{Rgs}}\right)\right] \cdot \phi,
$$

where $S_{\text {Iws }}$ is the irreducible water saturation, $\%$; $S_{\text {Rgs }}$ refers to the residual gas saturation, $\%$.

Test parameters related to the gas-water relative permeability test are shown in Table 2. The effective porosity of the samples varies between $2.84 \%$ and $6.20 \%$, with an average of $4.83 \%$. In this paper, the effective gas permeability (the maximum relative gas permeability) was used to represent the gas flow capacity of the rock sample. Table 2 indicates that the effective gas permeability ranges from $0.073 \times 10^{-3} \mu \mathrm{m}^{2}$ to $1.186 \times 10^{-3} \mu \mathrm{m}^{2}$, and the average is $0.482 \times 10^{-3} \mu \mathrm{m}^{2}$.

\subsection{Constant-Rate Mercury Injection}

Conventional mercury injection tests can well characterize the pore radius distribution in rocks ${ }^{30}$ For the sandstones with complex pore-throat structure, 


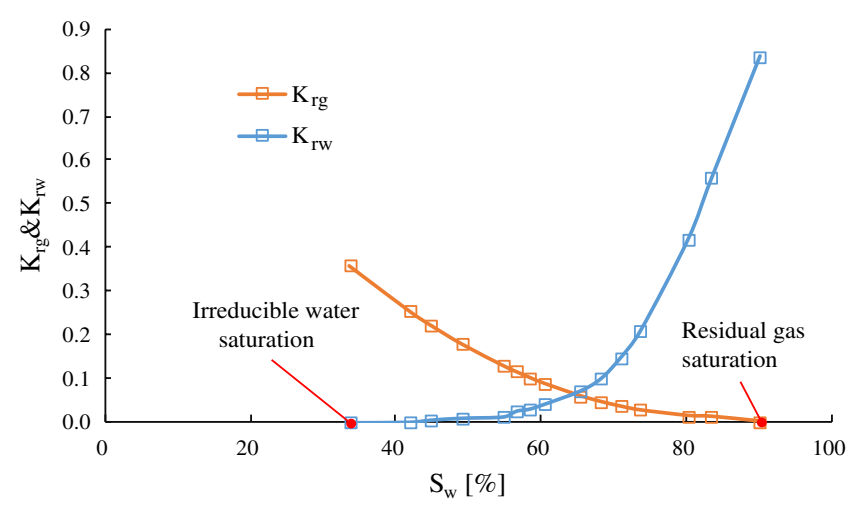

Fig. 2 Gas-water relative permeability of Sample D32-46.

Table 2 Flow and Physical Parameters Related to Gas-Water Relative Permeability Tests.

\begin{tabular}{|c|c|c|c|c|c|c|c|c|c|}
\hline Sample ID & $\begin{array}{c}\text { Depth } \\
{[\mathbf{m}]}\end{array}$ & $\begin{array}{l}\text { Length } \\
{[\mathrm{cm}]}\end{array}$ & $\begin{array}{c}\text { Diam } \\
{[\mathrm{cm}]}\end{array}$ & $\begin{array}{c}\text { Permeability } \\
{\left[\mathbf{1 0}^{-3} \boldsymbol{\mu} \mathbf{m}^{2}\right]}\end{array}$ & $\begin{array}{c}\text { Porosity } \\
{[\%]}\end{array}$ & $\begin{array}{c}\text { Residual Gas } \\
\text { Saturation } \\
{[\%]}\end{array}$ & $\begin{array}{c}\text { Irreducible } \\
\text { Water } \\
\text { Saturation [\%] }\end{array}$ & $\begin{array}{c}\text { Effective } \\
\text { Porosity } \\
{[\%]}\end{array}$ & $\begin{array}{c}\text { Effective Gas } \\
\text { Permeability } \\
{\left[\mathbf{1 0}^{-3} \boldsymbol{\mu \mathbf { m } ^ { 2 } ]}\right.}\end{array}$ \\
\hline D32-46 & 2989.28 & 3.462 & 2.501 & 0.565 & 10.55 & 9.932 & 33.685 & 5.95 & 0.203 \\
\hline D38-46 & 3026.23 & 4.649 & 2.501 & 0.282 & 4.55 & 2.945 & 34.548 & 2.84 & 0.122 \\
\hline D50-47-1 & 3106.30 & 3.201 & 2.500 & 0.703 & 9.14 & 2.489 & 54.020 & 3.98 & 0.209 \\
\hline D50-47-2 & 3108.17 & 4.923 & 2.501 & 0.489 & 9.04 & 6.474 & 49.002 & 4.02 & 0.219 \\
\hline S139 & 3642.88 & 4.927 & 2.492 & 2.237 & 15.02 & 1.778 & 61.500 & 5.52 & 0.991 \\
\hline S145 & 3134.60 & 2.895 & 2.497 & 0.753 & 7.47 & 6.883 & 26.270 & 4.99 & 0.349 \\
\hline $\mathrm{S} 173$ & 3125.96 & 3.158 & 2.501 & 2.332 & 9.49 & 11.867 & 24.722 & 6.02 & 0.807 \\
\hline $\mathrm{S} 179$ & 3143.15 & 3.001 & 2.501 & 0.703 & 9.14 & 2.489 & 29.690 & 6.20 & 0.366 \\
\hline $\mathrm{S} 231$ & 3143.00 & 2.999 & 2.500 & 2.834 & 13.95 & 4.947 & 50.635 & 6.20 & 0.502 \\
\hline $\mathrm{S} 243$ & 3047.56 & 5.236 & 2.492 & 0.335 & 8.83 & 11.102 & 48.561 & 3.56 & 0.074 \\
\hline S246-1 & 3027.50 & 3.021 & 2.501 & 1.071 & 10.05 & 5.989 & 45.851 & 4.84 & 0.442 \\
\hline S246-2 & 3049.00 & 3.007 & 2.499 & 1.272 & 10.37 & 6.884 & 52.126 & 4.25 & 0.398 \\
\hline S393 & 3666.42 & 4.020 & 2.500 & 0.679 & 11.01 & 10.655 & 42.808 & 5.12 & 0.398 \\
\hline $\mathrm{S} 48$ & 3625.06 & 4.724 & 2.501 & 0.771 & 13.98 & 13.190 & 44.820 & 5.87 & 0.620 \\
\hline S49 & 3635.68 & 4.785 & 2.505 & 0.939 & 10.23 & 16.100 & 48.000 & 3.67 & 0.825 \\
\hline S61 & 3610.44 & 4.657 & 2.497 & 2.225 & 15.07 & 11.144 & 48.551 & 6.07 & 1.186 \\
\hline $\mathrm{Z} 43$ & 3080.74 & 5.226 & 2.489 & 0.201 & 7.06 & 5.451 & 50.551 & 3.11 & 0.037 \\
\hline Z45-1 & 3131.14 & 5.102 & 2.500 & 0.686 & 7.33 & 5.481 & 27.613 & 4.90 & 0.312 \\
\hline Z45-2 & 3132.50 & 3.952 & 2.490 & 0.264 & 9.06 & 13.018 & 49.180 & 3.42 & 0.090 \\
\hline Z45-3 & 3137.23 & 4.239 & 2.501 & 1.783 & 9.31 & 14.098 & 20.426 & 6.09 & 0.697 \\
\hline
\end{tabular}

Note: The confining pressure for the pulse decay permeability measurement was $25 \mathrm{MPa}$, and the effective gas permeability is the gas permeability corresponding to the irreducible water saturation.

it is necessary to distinguish pores from throats. The fine tubular space that connects one pore to another is called a throat ${ }^{33}$ which greatly controls the fluid migration through reservoirs, especially in tight reservoirs. Hence, it is inappropriate to simply treat pores and throats as a whole. ${ }^{28135}$ The shapes of the 20 constant-rate mercury capillary pressure curves can be generally divided into three types. The first type is the pore type, which shows that in the large-throat rock, the mercury injection volume of pores rises rapidly and always exceeds that of throats, even after the mercury injection approaches the equilibrium (Fig. 3 $\mathrm{a}$ ). The second one is named as the transition type. For this type, the mercury injection volume of pores also surpasses that of throats, and it grows fast in the rock space with large throats. However, it is lower than the mercury volume injected into pores and exceeded by the volume into throats, as it enters the plateau (Fig. $3 \mathrm{~b}$ ). The last type is the throat type, which is characterized by the notably small amount of injected mercury filling pores, which is smaller than the mercury 


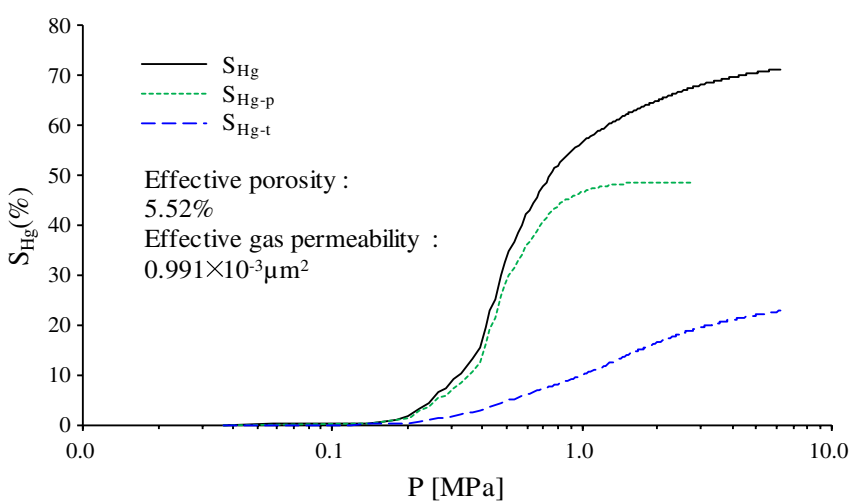

(a)

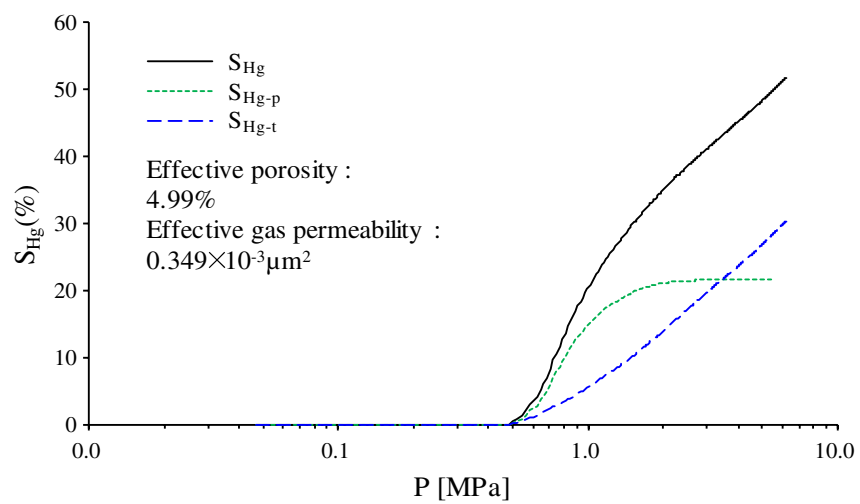

(b)

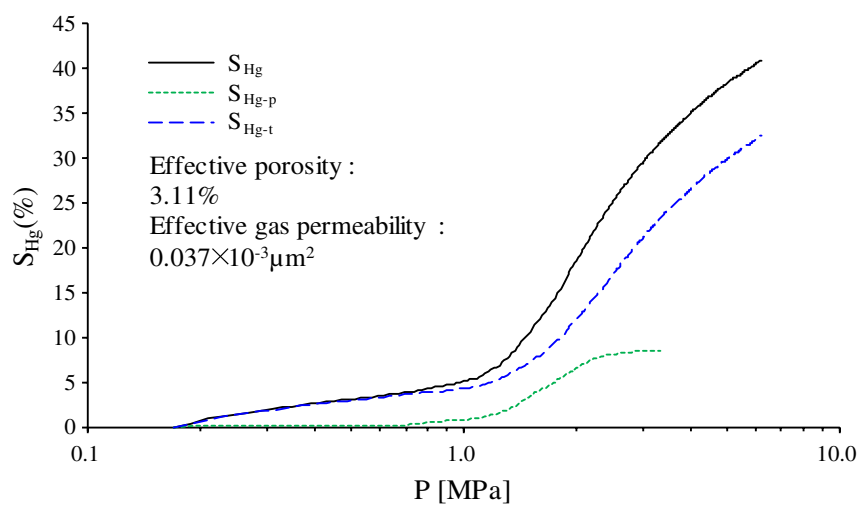

(c)

Fig. 3 Constant-rate mercury injection capillary pressure curves of Samples S139 (a), S149 (b) and Z43 (c).

amount in the throats even after the mercury injection reaches the equilibrium (Fig. 3). Moreover, the three samples shown in Fig. 3 indicate that as the pore-throat structure changes from the pore type to the throat type, the effective porosity and the relative gas permeability gradually decrease. Previous studies show that the pore type is superior to the transition type, while the transition type further overmatches the throat type from perspectives of hydrocarbon exploration and development ${ }^{[7}$ It has been demonstrated that physical properties of poretype rocks are not necessarily better than those with throat-type ones with large void space. Therefore, this paper did not focus on the shape classification of constant-rate mercury injection-based capillary pressure curves.

Yet, it is safe to say that pores and throats play vital roles in the physical property of tight gas sandstones of the Shihezi Formation, based on the correlation between the shape of the constant-mercury injection capillary pressure curves and the effective physical property of rocks.

\subsection{Constant-Rate Mercury Injection-Based Pore-Throat Structures}

Basically, the pore-throat structure can be characterized by the displacement pressure, pore-throat radius and volume, and total mercury saturation. The basic pore-throat structure parameters of 20 tight gas sandstone samples measured via the constant mercury injection are listed in Table 3. The displacement pressure, defined as the least pressure that is required by the non-wetting phase to displace the wetting phase, captures the general porethroat structure of the rock $!^{[1 / 30}$ The measured displacement pressures of the 20 samples lie between $0.17 \mathrm{MPa}$ and $1.10 \mathrm{MPa}$, averaging $0.56 \mathrm{MPa}$. On the basis of the equivalent spherical model, the calculated average pore radius ranges from $142.41 \mu \mathrm{m}$ to $173.13 \mu \mathrm{m}$, with an average of $155.30 \mu \mathrm{m}$, which far exceeds the average throat radius of $0.35 \mu \mathrm{m}-$ $1.84 \mu \mathrm{m}$, averaging $0.90 \mu \mathrm{m}$. The total mercury saturation is from $19.26 \%$ to $73.83 \%$, and the mean 
Table 3 Constant-Rate Mercury Injection-Based Pore-Throat Structure Parameters.

\begin{tabular}{|c|c|c|c|c|c|c|c|}
\hline Sample ID & $\begin{array}{c}\text { Depth } \\
{[\mathbf{m}]}\end{array}$ & $\begin{array}{c}\text { Displacement } \\
\text { Pressure } \\
{[\mathrm{MPa}]}\end{array}$ & $\begin{array}{c}\text { Average } \\
\text { Pore Radius } \\
{[\mu \mathrm{m}]}\end{array}$ & $\begin{array}{c}\text { Average } \\
\text { Throat Radius } \\
{[\mu \mathrm{m}]}\end{array}$ & $\begin{array}{c}\text { Pore } \\
\text { Volume } \\
{\left[\mathrm{cm}^{3} / \mathrm{g}\right]}\end{array}$ & $\begin{array}{l}\text { Throat } \\
\text { Volume } \\
{\left[\mathrm{cm}^{3} / \mathrm{g}\right]}\end{array}$ & $\begin{array}{c}\text { Mercury } \\
\text { Saturation } \\
{[\%]}\end{array}$ \\
\hline D32-46 & 2989.28 & 0.35 & 153.31 & 0.87 & 6.71 & 10.55 & 38.93 \\
\hline D38-46 & 3026.23 & 0.60 & 143.99 & 0.73 & 0.46 & 3.42 & 20.61 \\
\hline D50-47-1 & 3106.30 & 0.57 & 142.41 & 0.70 & 3.27 & 11.87 & 39.26 \\
\hline D50-47-2 & 3108.17 & 0.77 & 164.43 & 0.54 & 10.11 & 9.54 & 53.91 \\
\hline S139 & 3642.88 & 0.20 & 167.64 & 1.64 & 29.79 & 13.93 & 71.32 \\
\hline S145 & 3134.60 & 0.50 & 159.16 & 0.86 & 6.71 & 9.41 & 51.79 \\
\hline S173 & 3125.96 & 0.29 & 168.78 & 1.22 & 14.15 & 11.13 & 63.41 \\
\hline S179 & 3143.15 & 0.68 & 148.72 & 0.71 & 3.92 & 9.73 & 36.31 \\
\hline $\mathrm{S} 231$ & 3143.00 & 0.21 & 173.13 & 1.71 & 19.30 & 15.42 & 58.73 \\
\hline $\mathrm{S} 243$ & 3047.56 & 0.86 & 145.84 & 0.35 & 3.39 & 14.80 & 49.45 \\
\hline S246-1 & 3027.50 & 0.18 & 146.79 & 1.84 & 8.49 & 11.87 & 48.01 \\
\hline S246-2 & 3049.00 & 0.57 & 167.44 & 0.78 & 13.52 & 12.54 & 61.57 \\
\hline S393 & 3666.42 & 0.33 & 168.74 & 1.07 & 23.94 & 8.96 & 73.83 \\
\hline $\mathrm{S} 48$ & 3625.06 & 0.92 & 159.95 & 0.57 & 21.27 & 18.26 & 68.98 \\
\hline S49 & 3635.68 & 1.07 & 145.93 & 0.52 & 3.61 & 13.97 & 42.78 \\
\hline S61 & 3610.44 & 0.17 & 152.61 & 1.20 & 16.71 & 28.11 & 71.09 \\
\hline $\mathrm{Z} 43$ & 3080.74 & 1.10 & 143.64 & 0.41 & 2.48 & 9.50 & 40.90 \\
\hline Z45-1 & 3131.14 & 0.63 & 152.57 & 0.79 & 1.72 & 4.04 & 19.26 \\
\hline Z45-2 & 3132.50 & 0.70 & 151.78 & 0.55 & 8.54 & 17.95 & 69.88 \\
\hline Z45-3 & 3137.23 & 0.41 & 149.23 & 1.00 & 9.81 & 13.01 & 57.87 \\
\hline
\end{tabular}

is $51.89 \%$. Furthermore, the pore volume is calculated as $0.46 \mathrm{~cm}^{3} / \mathrm{g}-29.79 \mathrm{~cm}^{3} / \mathrm{g}$, with an average of $10.40 \mathrm{~cm}^{3} / \mathrm{g}$, and the throat volume, $3.42 \mathrm{~cm}^{3} / \mathrm{g}-$ $28.11 \mathrm{~cm}^{3} / \mathrm{g}$, averaging $12.40 \mathrm{~cm}^{3} / \mathrm{g}$.

\subsection{Constant-Rate Mercury Injection-Based Fractal Dimensions}

The concept of fractal dimensions was first introduced in 1975. It is believed that fractal dimensions can quantitatively describe solids with fractal features. Moreover, they can provide direct comparisons of structure irregularity and surface complexity among different solids. The fractal dimension's lower limit, 2, indicates homogeneous structures or smooth surfaces with strong selfsimilarity, while the upper limit 3 means completely heterogeneous structures or extremely rugged surfaces with poor self-similarity ${ }^{[36}$ Fractal analysis has been widely applied to object geometry characterization, e.g. from greyscale image analyses ${ }^{37}$ to pore structures of porous media,,$\frac{38 \mid 39}{3}$ and from fracture networks 40141 to larger-scale sand body macroscopic characteristics. ${ }^{6 / 42}$ It is also important for the evaluation of the reservoir quality. This paper separated pores from throats, as is shown in Fig. $4 a$, and respectively calculated their fractal dimensions $\left(V_{r p}\right.$ and $\left.V_{r t}\right)$. This avoids mixing $V_{r p}$ and $V_{r t}$ of pores and throats that have similar sizes but impose varied effects on the rock-fluid interaction (Fig. 4b).

According to the fractal theory, for the porethroat structure endowed with fractal features, the quantity $(N)$ of pores and throats with radii over a specific value $r$ follows the following function $3643+45$.

$$
N(\geq r)=\int_{r}^{r_{\max }} P(r) d r=a r^{-D},
$$

where $r_{\max }$ refers to the maximum pore-throat radius, $\mu \mathrm{m} ; P(r)$ is the probability density function of the pore-throat radius; $a$ is a constant, dimensionless; $D$ represents the fractal dimension.

Equation (3) is obtained by derivation of Eq. (21) with respect to $r$ :

$$
P(r)=\frac{d N(\geq r)}{d r}=-\operatorname{Dar}^{-D-1} .
$$

The tubular bundle model is used for the mercury injection test, and thus the cumulative pore-throat volume with radii over $r$ can be calculated as below:

$$
V(\geq r)=\int_{r}^{r_{\max }} P(r) \pi r^{2} l d r
$$

where $l$ refers to the length of the tubular bundle model.

Studies show that a linear correlation is found between $l$ and $r, \underline{46}$ and therefore Eq. (4) can be 


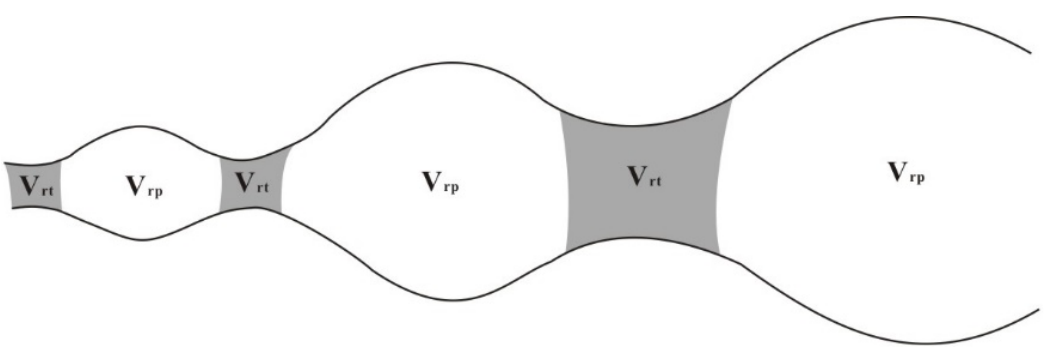

(a)

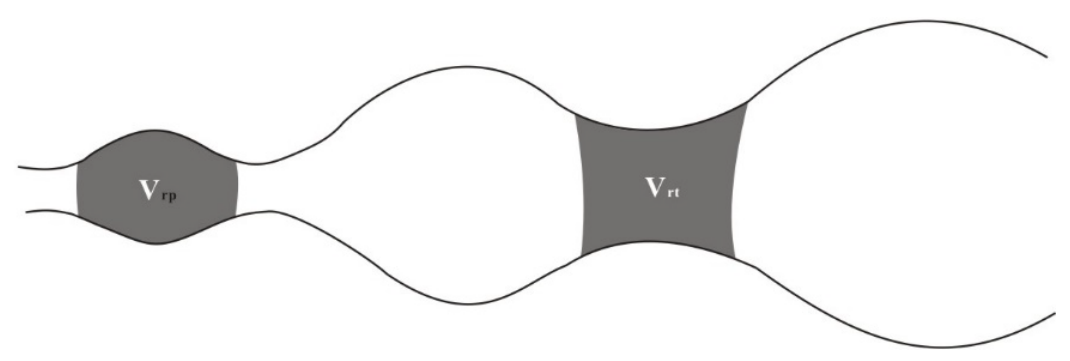

(b)

Fig. 4 Schematic diagrams of pores and throats.

rearranged into

$$
V(\geq r)=\int_{r}^{r_{\max }} P(r) \pi b r^{3} d r
$$

where $b$ is a constant, dimensionless.

Combining Eqs. (3) and (5) yields

$$
\begin{aligned}
V(\geq r) & =\int_{r}^{r_{\max }}-D a \pi b r^{2-D} d r=\left.\frac{D a \pi b}{D-3} r^{3-D}\right|_{r} ^{r_{\max }} \\
& =\frac{D a \pi b}{D-3}\left(r_{\max }^{3-D}-r^{3-D}\right) .
\end{aligned}
$$

Accordingly, the total pore-throat volume $V_{0}$ can be written as

$$
V_{0}=\frac{D a \pi b}{D-3}\left(r_{\max }^{3-D}-r_{\min }^{3-D}\right),
$$

where $r_{\min }$ is the least pore-throat radius, $\mu \mathrm{m}$.

According to Eqs. (6) and (7), the mercury saturation $S_{H g}$ in the samples with pore radius greater than $r$ is

$$
S_{H g}(\geq r)=\frac{V(\geq r)}{V_{0}}=\frac{r_{\max }{ }^{3-D}-r^{3-D}}{r_{\max }{ }^{3-D}-r_{\min }^{3-D}} .
$$

Because the maximum pore-throat radius far surpasses the minimum one, Eq. (8) can then be written as

$$
S_{H g}(\geq r)=\frac{r_{\max }^{3-D}-r^{3-D}}{r_{\max }^{3-D}}=1-\left(\frac{r}{r_{\max }}\right)^{3-D} \text {. }
$$

The derivative of Eq. (9) with respect to $r$ is calculated as

$$
\lg \left[1-S_{H g}(\geq r)\right]=(3-D) \lg r-(3-D) \lg r_{\max } .
$$

Then fractal dimension $D$ can be calculated from the correlation between $l g\left[1-S_{H g}(\geq r)\right]$ and $l g r$, which is shown below:

$$
\begin{aligned}
3-D & =k, \\
D & =3-k,
\end{aligned}
$$

where $k$ represents the slope of the linear correlation between $\lg \left[1-S_{H g}(\geq r)\right]$ and $\lg r$.

In addition, since the equivalent spherical model is used for the pore radius calculation, Eq. (4) can be rearranged into

$$
V(\geq r)=\int_{r}^{r_{\max }} P(r) \frac{4}{3} \pi r^{3} d r
$$

It is found that substitution of $b=4 / 3$ into Eqs. (5) -(17) has no effect on Eq. (10). Thus, the fractal dimensions of pores and throats $D_{p}$ and $D_{t}$ can be respectively calculated, on the basis of corresponding correlations between $\lg \left[1-S_{H g}(\geq r)\right]$ and $\lg r$. Fractal dimensions of pores and throats of the 20 tight gas sandstone samples from the Shihezi Formation were calculated using the constant-rate mercury injection data. It is shown that the fractal dimension of pores can be divided into three ranges, fractal dimensions $D_{p 1}, D_{p 2}$ and $D_{p 3}$, in 
accordance with ascending pore radii (Fig. 5 a). Correspondingly, the fractal dimension of throats can be divided into two ranges, fractal dimensions $D_{t 1}$ and $D_{t 2}$, with respect to ascending throat radii (Fig. 5b). The fractal dimension calculation results and corresponding correlation coefficients $R^{2}$ are concluded in Table 4 . Fractal dimension $D_{p 1}$ ranges from 2.9157 to 2.9991, averaging 2.9763. However, it was not discussed in this paper, given that corresponding $R^{2}$ lies between 0.7415 and 0.9900 , with an average of 0.8491 , indicating lower correlation; data points for lower pore radii were limited; the pore radius was calculated on the basis of the equivalent spherical model. Fractal dimension
$D_{p 2}$ is 2.1098-2.9116 and averages 2.6500, with $R^{2}$ of 0.9423 to 0.9919 , averaging 0.9705 . Furthermore, fractal dimension $D_{p 3}$ is $2.9423-2.9900$ and averages 2.9711, with $R^{2}$ of 0.9023 to 0.9641 , averaging 0.9305 . This suggests that larger pores excel in complexity, compared with smaller ones. Fractal dimension $D_{t 1}$ is $2.5160-2.9235$ and averages 2.7833 , with $R^{2}$ of $0.9761-0.9990$, averaging 0.9939. Fractal dimension $D_{t 2}$ is $2.8690-2.9767$ and averages 2.9342, with $R^{2}$ of $0.9282-0.9914$, averaging 0.9706 . Fractal dimension $D_{t 1}$ is relatively smaller, which means that large throats are more complex than small ones. This is probably because that smaller pores and throats generally

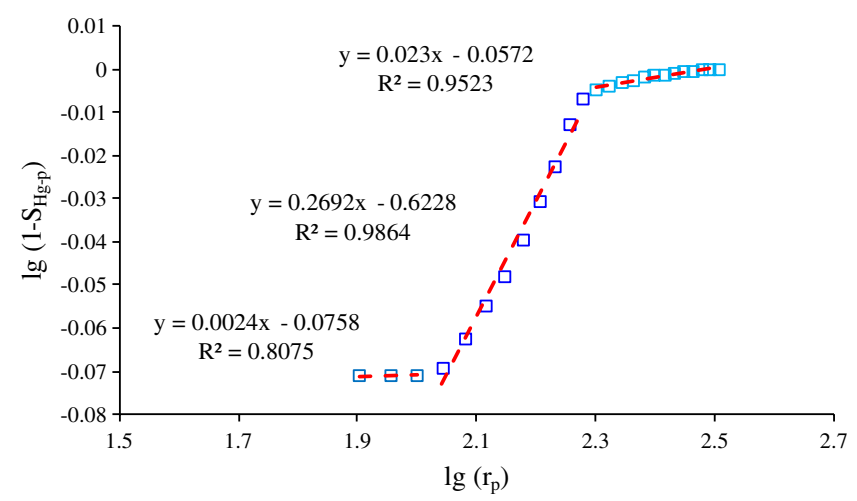

(a)

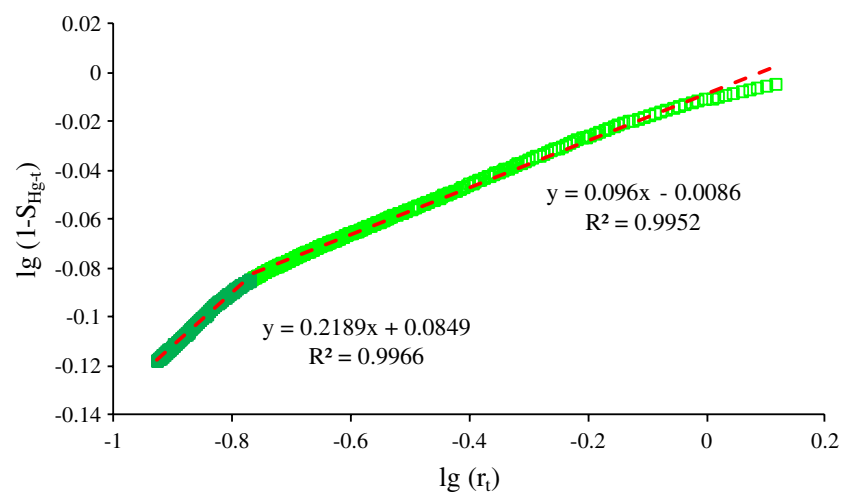

(b)

Fig. 5 Cross-plots of constant-rate mercury injection-based $l g\left[1-S_{H g}(\geq r)\right]$ versus $l g r$ of pores (a) and throats (b), Sample D32-46.

Table 4 Fractal Dimension Calculation of Pores and Throats.

\begin{tabular}{|c|c|c|c|c|c|c|c|c|c|c|c|}
\hline Sample ID & Depth $[\mathrm{m}]$ & $D_{p 1}$ & $R^{2}$ & $D_{p 2}$ & $R^{2}$ & $D_{p 3}$ & $R^{2}$ & $D_{t 1}$ & $R^{2}$ & $D_{t 2}$ & $R^{2}$ \\
\hline D32-46 & 2989.28 & 2.9976 & 0.8075 & 2.7308 & 0.9864 & 2.9770 & 0.9523 & 2.7811 & 0.9966 & 2.9040 & 0.9952 \\
\hline D38-46 & 3026.23 & 2.9951 & 0.8658 & 2.9612 & 0.9879 & 2.9968 & 0.9845 & 2.8701 & 0.9939 & 2.9347 & 0.9833 \\
\hline D50-47-1 & 3106.30 & 2.9983 & 0.8487 & 2.8554 & 0.9872 & 2.9941 & 0.8589 & 2.7841 & 0.9984 & 2.9179 & 0.9830 \\
\hline D50-47-2 & 3108.17 & 2.9960 & 0.8017 & 2.3819 & 0.9458 & 2.9742 & 0.9059 & 2.7741 & 0.9989 & 2.9009 & 0.9882 \\
\hline S139 & 3642.88 & 2.9946 & 0.7824 & 2.1377 & 0.9774 & 2.9014 & 0.9103 & 2.9449 & 0.9958 & 2.9042 & 0.9949 \\
\hline S145 & 3134.60 & 2.8398 & 0.8377 & 2.7316 & 0.9304 & 2.9825 & 0.9299 & 2.8232 & 0.9969 & 2.9044 & 0.9907 \\
\hline S173 & 3125.96 & 2.9874 & 0.8314 & 2.5078 & 0.9731 & 2.9640 & 0.9146 & 2.8555 & 0.9965 & 2.9318 & 0.9761 \\
\hline $\mathrm{S} 179$ & 3143.15 & 2.9813 & 0.8033 & 2.8363 & 0.9875 & 2.9789 & 0.9023 & 2.8147 & 0.9990 & 2.9325 & 0.9610 \\
\hline $\mathrm{S} 231$ & 3143.00 & 2.9279 & 0.7446 & 2.6406 & 0.9611 & 2.9423 & 0.9328 & 2.8762 & 0.9981 & 2.9613 & 0.9638 \\
\hline $\mathrm{S} 243$ & 3047.56 & 2.9837 & 0.7415 & 2.8577 & 0.9822 & 2.9707 & 0.9641 & 2.7313 & 0.9964 & 2.9596 & 0.9282 \\
\hline S246-1 & 3027.50 & 2.9918 & 0.7560 & 2.6366 & 0.9866 & 2.9793 & 0.9540 & 2.8925 & 0.9930 & 2.9239 & 0.9861 \\
\hline S246-2 & 3049.00 & 2.9817 & 0.7819 & 2.5728 & 0.9423 & 2.9792 & 0.9486 & 2.8120 & 0.9967 & 2.9101 & 0.9860 \\
\hline S393 & 3666.42 & 2.9157 & 0.8285 & 2.1098 & 0.9551 & 2.9428 & 0.9107 & 2.9078 & 0.9862 & 2.9300 & 0.9914 \\
\hline S48 & 3625.06 & 2.9936 & 0.9786 & 2.4923 & 0.9460 & 2.9777 & 0.9237 & 2.7384 & 0.9979 & 2.9207 & 0.9659 \\
\hline S49 & 3635.68 & 2.9988 & 0.8888 & 2.8614 & 0.9854 & 2.9856 & 0.9092 & 2.6748 & 0.9897 & 2.8690 & 0.9802 \\
\hline S61 & 3610.44 & 2.9991 & 0.9680 & 2.5810 & 0.9778 & 2.9792 & 0.9083 & 2.5160 & 0.9761 & 2.8797 & 0.9826 \\
\hline $\mathrm{Z} 43$ & 3080.74 & 2.9986 & 0.9442 & 2.8314 & 0.9689 & 2.9750 & 0.9334 & 2.7665 & 0.9955 & 2.9767 & 0.9818 \\
\hline Z45-1 & 3131.14 & 2.9987 & 0.8313 & 2.9116 & 0.9919 & 2.9900 & 0.9595 & 2.9235 & 0.9954 & 2.9764 & 0.9765 \\
\hline Z45-2 & 3132.50 & 2.9547 & 0.9900 & 2.6421 & 0.9704 & 2.9664 & 0.9449 & 2.6693 & 0.9962 & 2.9757 & 0.9646 \\
\hline Z45-3 & 3137.23 & 2.9554 & 0.7993 & 2.6185 & 0.9583 & 2.9648 & 0.9205 & 2.7943 & 0.9981 & 2.9316 & 0.9438 \\
\hline
\end{tabular}


have better regularity and continuity, while larger pores and throats are sparsely distributed with poor connectivity and thus have relatively high fractal dimensions. In addition, the pore radius corresponding to the turning point of the throat fractal dimension curve varies with different samples, and so do the measured maximum radii of pores and throats. Therefore, this paper divided pores into the small and large pore space, while throats were similarly classified as the small and large throat space. Detailed discussion of the correlation between different fractal dimensions and pore-throat structures is summarized below, and so is the discussion on the effects of different fractal dimensions on the effective physical property.

\section{DISCUSSION}

In order to explore each fractal dimension's effects on the effective physical property, analyses on correlations between fractal dimensions, porethroat structures and mineral compositions are necessary.

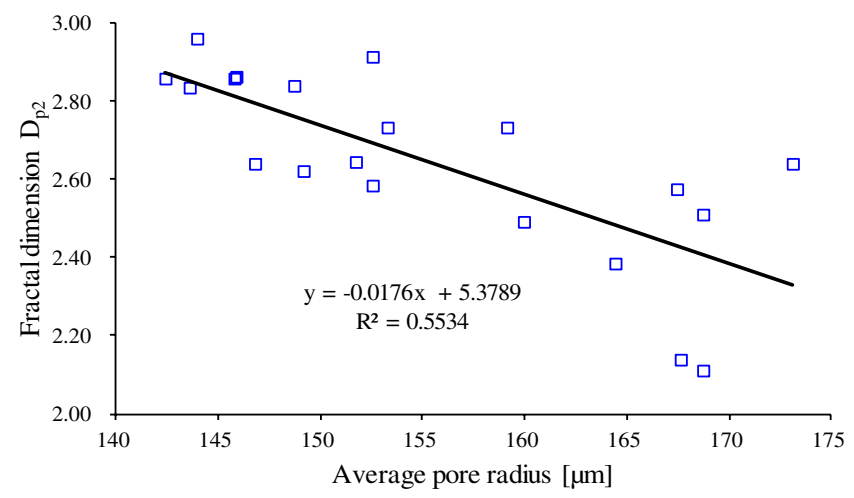

(a)

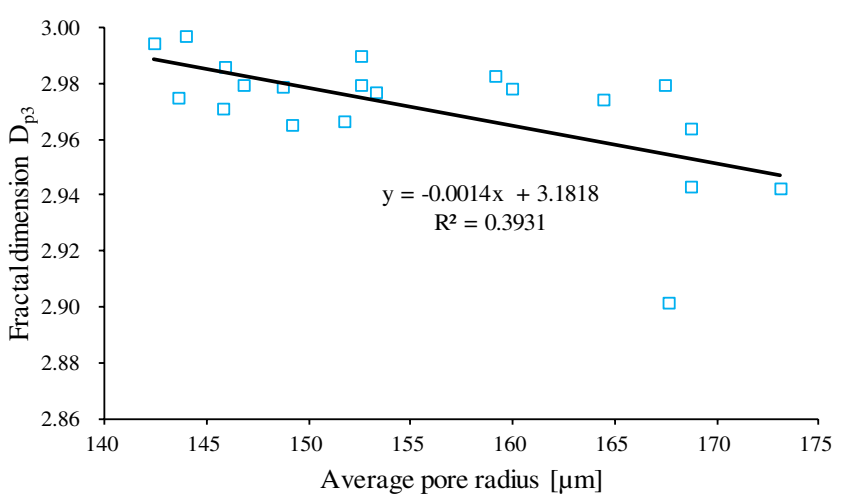

(c)

\subsection{Correlation Between Fractal Dimensions and Pore-Throat Structures}

All pore-throat structure parameters (shown in Table 3) are plotted versus fractal dimensions in Figs. $6 \mathrm{a}-6 \mathrm{n}$, so as to shed light upon the roles that pore-throat structures play in varied tight gas sandstone samples.

Fractal dimensions $D_{p 2}$ and $D_{p 3}$ present relatively good negative correlations with the average pore radius (Figs. 6a and 6r). A lower average pore radius indicates finer pores, which results in pore structures with higher heterogeneity and complexity and hence increases in fractal dimensions $D_{p 2}$ and $D_{p 3}$. These fine pores that raises up the complexity of the pore structure suppress the fluid migration through the pore network. That is to say, higher fractal dimensions $D_{p 2}$ and $D_{p 3}$ harm the gas-liquid exchange process.

Fractal dimension $D_{t 1}$ shows a weak positive relationship with the average throat radius (Fig. 6e), and yet fractal dimension $D_{t 2}$ cannot be clearly

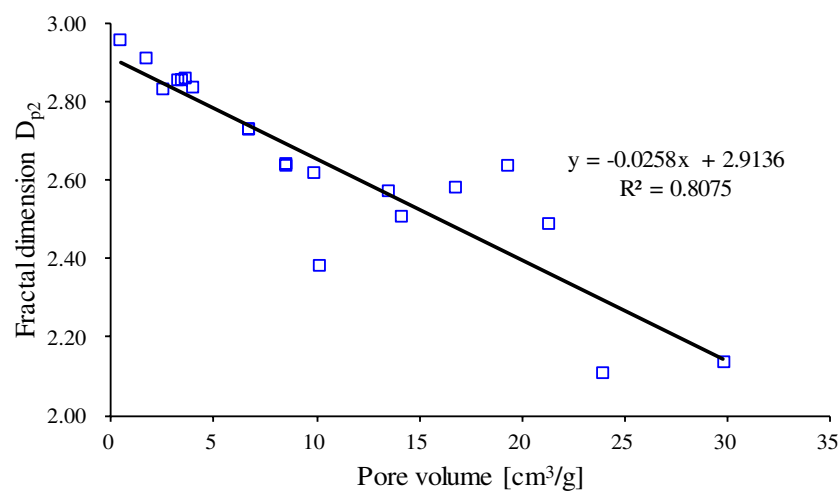

(b)

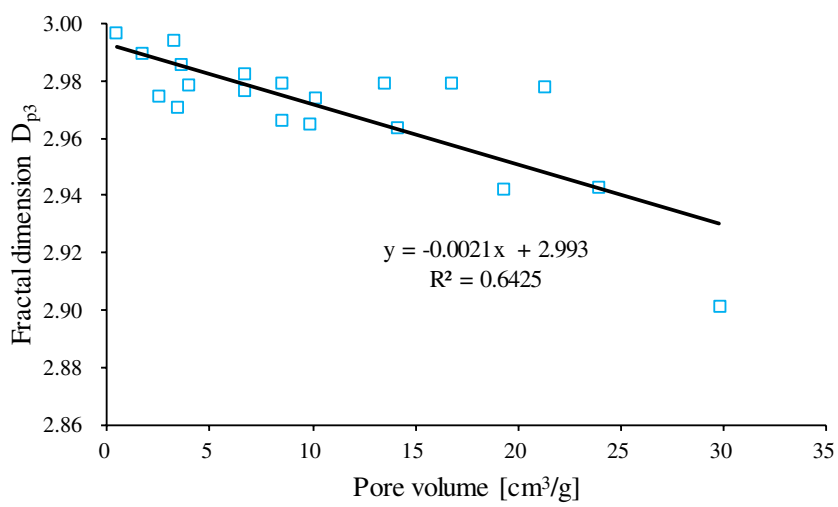

(d)

Fig. 6 Fractal dimensions $D_{p 2}$ and $D_{p 3}$ versus average pore radii and volumes (a)-(d); Fractal dimensions $D_{t 1}$ and $D_{t 2}$ versus average throat radii and volumes (e)-(h). 


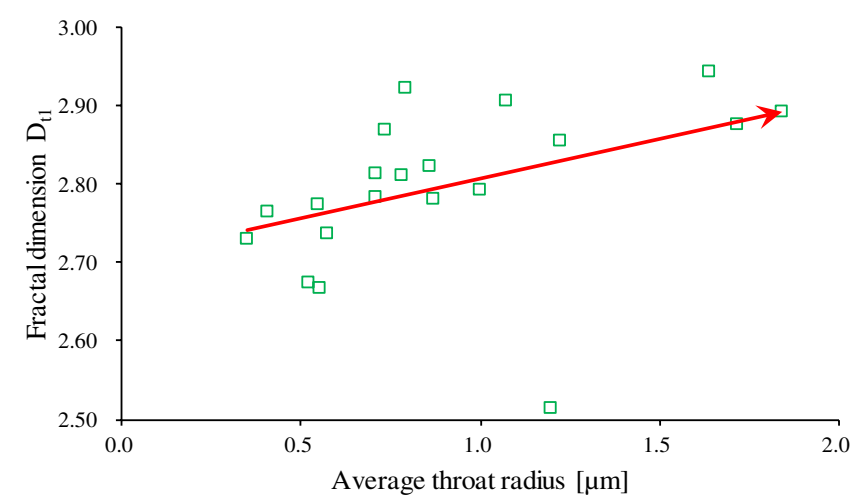

(e)

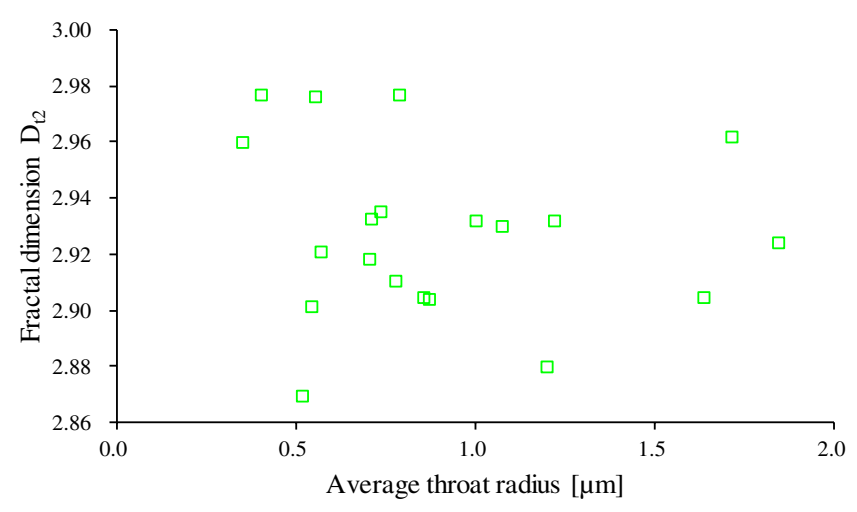

(g)

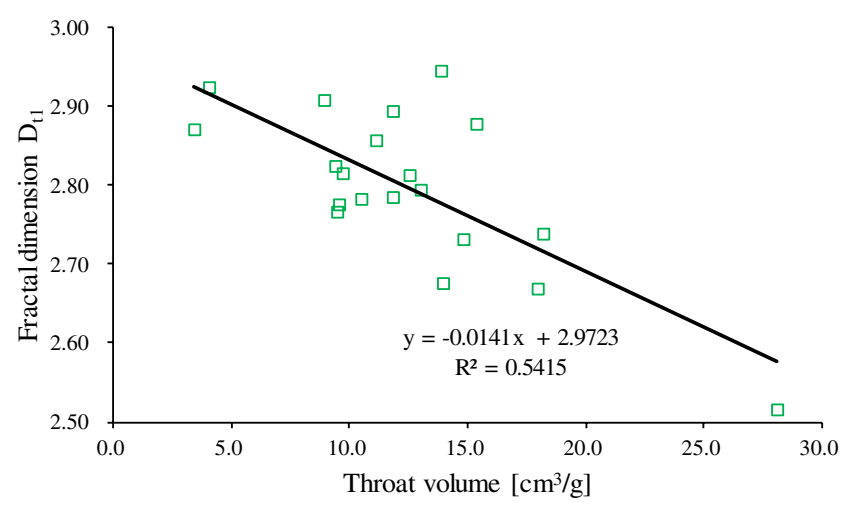

(f)

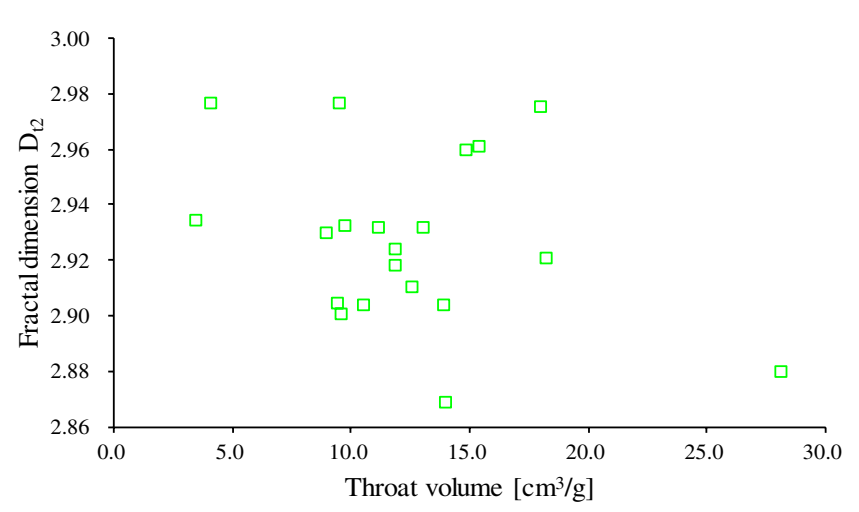

(h)

Fig. 6 (Continued)

correlated with the average throat radius (Fig. 6b). This demonstrates that the effects of the average throat radius on fractal dimensions $D_{t 1}$ and $D_{t 2}$ are distinct, and much smaller than those of the average pore radius on the pore fractal dimension. Compared with pores with bloated shapes (Fig. 7d), throats with flake-like and curved shapes (Figs. 7b and 7b) have significantly diversified tortuosity. Interstitial materials, especially clay minerals, further aggravate the structural complexity of throats (Figs. $7 \mathrm{a}-7 \mathrm{~d}$ ). Hence, throats have complicated self-similarity, owing to their flake-like and curved shapes, and present high irregularity, even though the average throat radius rises.

A notable negative correlation with $R^{2}=$ 0.8075 and a relatively strong one are respectively observed between the pore volume and fractal dimensions $D_{p 2}$, and $D_{p 3}$ (Figs. 6 $\mathrm{b}$ and $6 \mathrm{~d}$ ). Fractal dimensions $D_{p 2}$ and $D_{p 3}$ grow with reducing pore volumes, which indicate that the complexity of the pore structure increases with higher pore volumes. In addition, the correlation between fractal dimension $D_{p 2}$ and the pore volume is higher than that between fractal dimension $D_{p 3}$ and the pore volume, suggesting that the pore volume variation has stronger effects on the small pore space. It can be concluded that smaller fractal dimensions $D_{p 2}$ and $D_{p 3}$ are capable of enlarging the theoretical space for gas-liquid exchange.

Between fractal dimension $D_{t 1}$ and the throat volume, a favorable negative correlation with $R^{2}=$ 0.5415 is found, suggesting that higher fractal dimension $D_{t 1}$ leads to lower throat volumes in tight gas sandstones. For fractal dimension $D_{t 2}$, its relationship with the throat volume is vague (Fig. 6h). It can be inferred that the influence of throat volume on fractal dimension $D_{t 1}$ should be much more intensive than that on fractal dimension $D_{t 2}$. It is consequently suggested that $D_{t 1}$ should be a better representative of the fractal dimension of throats as a whole than $D_{t 2}$ due to its higher sensitivity to the variation in the throat volume. Therefore, it can be concluded that fractal dimension $D_{t 1}$ captures the complexity of the throat structure, as it can better reflect the throat volume as is discussed above. Shrunk throat volumes lead to increased fractal dimension $D_{t 1}$ and also exacerbated difficulty in fluid flow. 

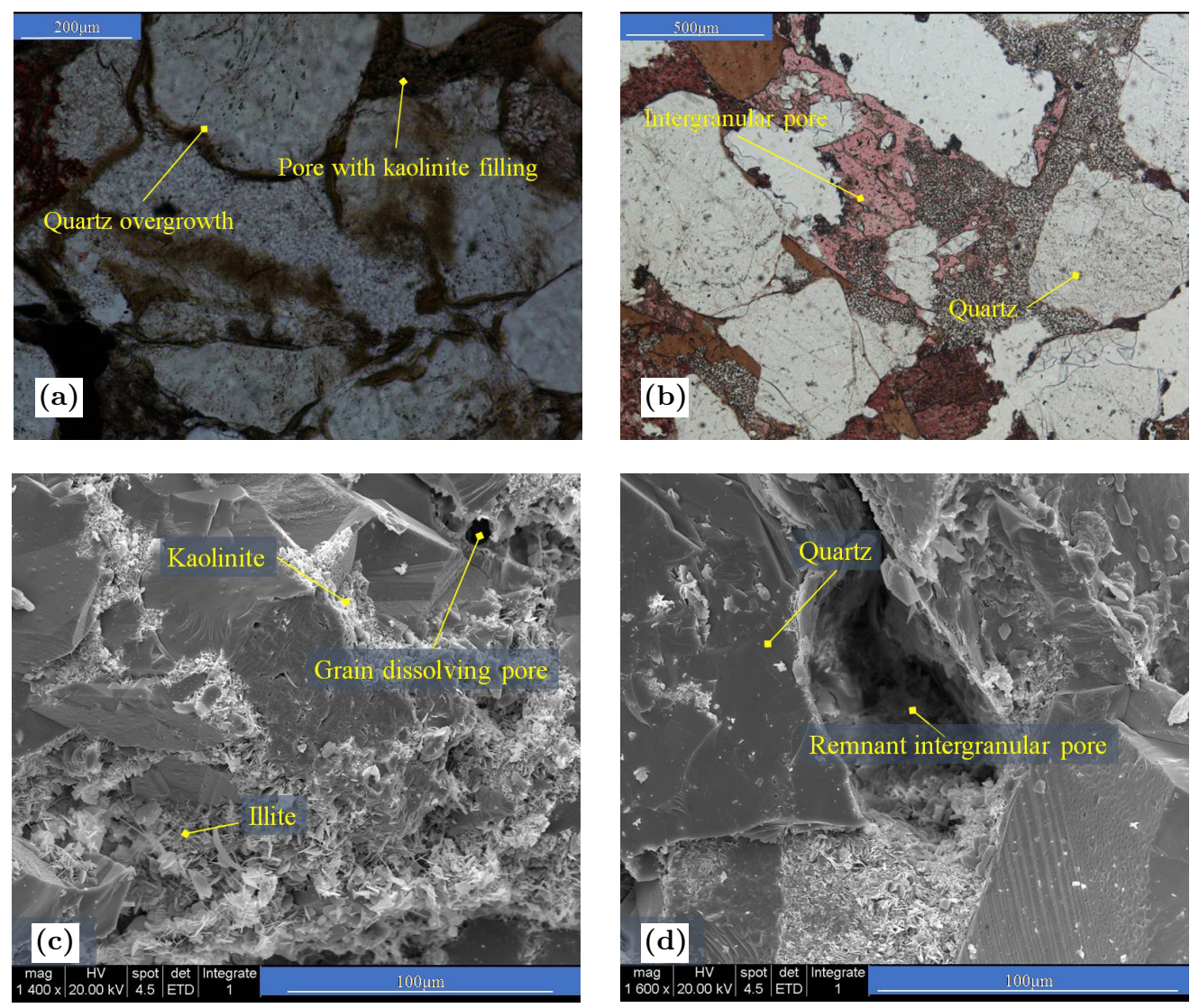

Fig. 7 Casting thin-section photos of Sample Z43 (a) and (b), and SEM photos of Samples S246-1 (c) and S145 (d).

\subsection{Correlation Between Fractal Dimensions and Mineral Compositions}

For a better understanding of the effects of mineral compositions on fractal dimensions of the tight gas sandstone from the Shihezi Formation, fractal dimensions and each mineral composition are all plotted in Fig. 8. Because of its very low content (0-2\%), the feldspar was neglected in the analysis. As is shown in the figure, the fractal dimension of throats and the corresponding self-similarity are more subjected to the shape characteristic of throats, compared with those of pores. For instance, Fig. 8 indicates certain correlation of the pore fractal dimension with quartz, lithic fragment and interstitial material contents, while there is no clear relationship between throat fractal dimension and any mineral composition.

Fractal dimensions $D_{p 2}$ and $D_{p 3}$ are both, to some extent, negatively correlated with the quartz content (Figs. 8 a and $8 \mathrm{~d}$ ), and positively related to the contents of lithic fragments and interstitial materials (Figs. $8 \mathrm{~b}, 8 \mathrm{c}, 8 \mathrm{p}$ and $8 \mathrm{f}$ ). This means that more quartz favors the improvement of complexity of both large and small pores, while increasing lithic fragments or interstitial materials intensifies the complexity. This may be attributed to the smoother surface of quartz, compared with those of lithics and interstitial materials. As the quartz content grows, pores become smoother. In contrast, the pore structure will be more complicated, with higher contents of lithic fragments that are more ductile, and interstitial materials with more complex crystal structures. In such cases, fractal dimensions $D_{p 2}$ and $D_{p 3}$ correspondingly climb up. Besides, it is found that the correlation between the pore fractal dimension and the quartz content is superior to those between the pore fractal dimension and the lithic fragment content or the interstitial material content, which is probably led by the lithic fragmentinterstitial material interaction. Meanwhile, the correlations between the fractal dimension of the small pore space and mineral compositions outrun those regarding the large pore space (Figs. $8 a-8$ ). The reason for this may be that the improvement of selfsimilarity achieved by the desirable mineral composition variation is limited, owing to the large contact 
H. Huang et al.

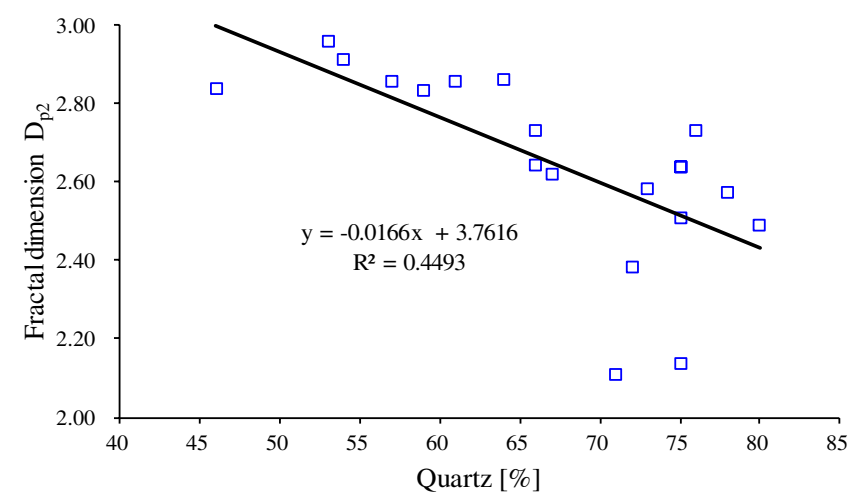

(a)

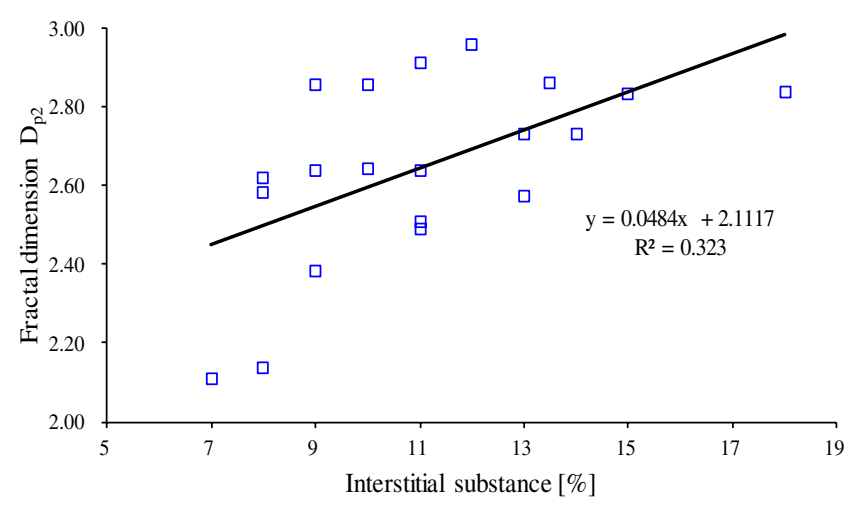

(c)

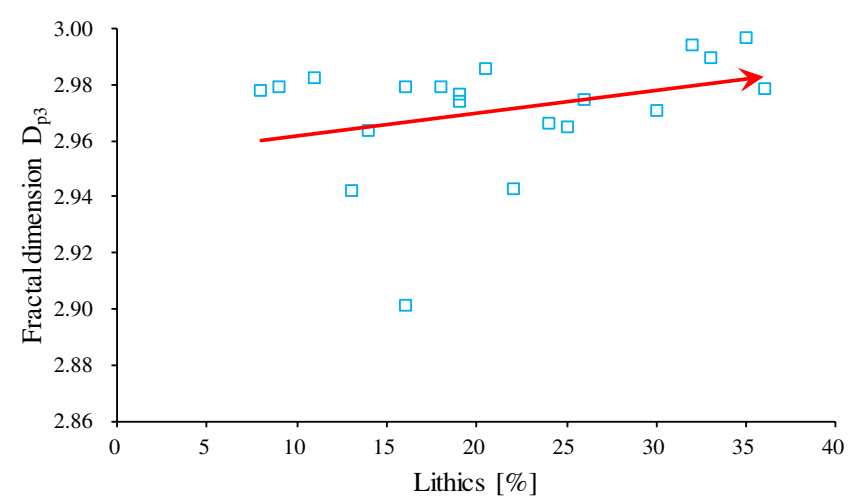

(e)



(b)

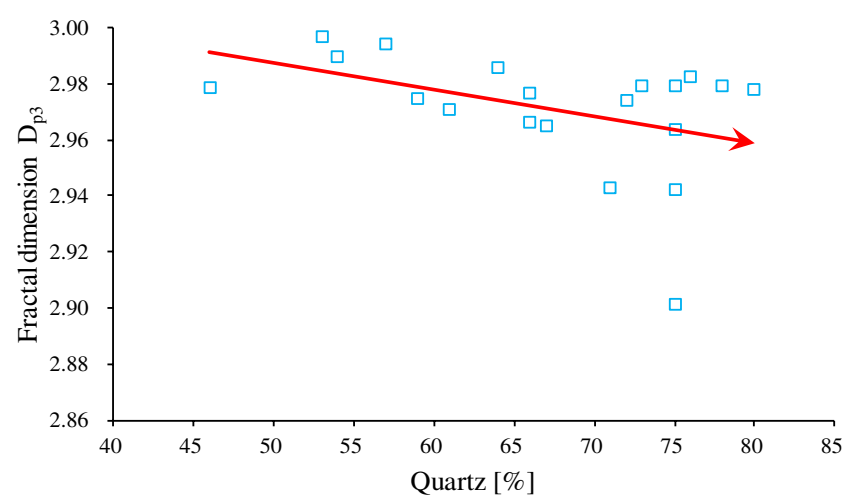

(d)

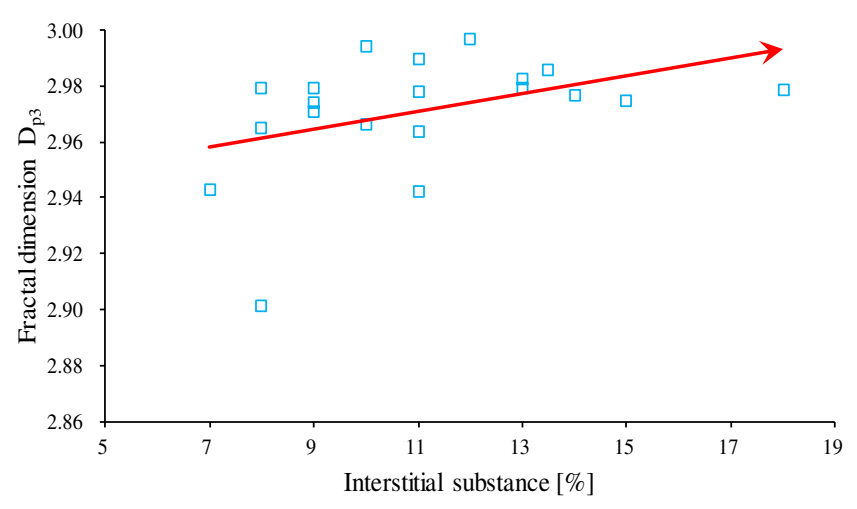

(f)

Fig. 8 Fractal dimensions $D_{p 2}$ and $D_{p 3}$ versus quartz, lithic fragment and interstitial material contents (a)-(f); Fractal dimensions $D_{t 1}$ and $D_{t 2}$ versus quartz, lithic fragment and interstitial material contents $(\mathrm{g})-(\mathrm{l})$.

area between large pores and rock minerals. Thus, the mineral content variation has stronger effects on the fractal dimension of small pore space.

Negative correlations between throat fractal dimensions and quartz contents are hardly seen (Figs. $8 \mathrm{~g}$ and $8 \mathrm{j}$ ). Similarly, the positive correlations between the throat fractal dimension and the lithic fragment and interstitial material contents are rarely noticeable (Figs. 87, 81, 8k and 8]). Thus, it can be concluded that the complexity of the throat structure is hardly relevant to the mineral composition. This observation contradicts the usual understanding that more quartz increases porethroat homogeneity while more lithics or interstitial materials complicate the pore-throat structure. One assumption for this is that the flake-like and curved throats offset the influence of mineral compositions (Figs. 77 and 7b). 
Pore-Throat Structure and Fractal Characteristics of Shihezi Formation Tight Gas Sandstone

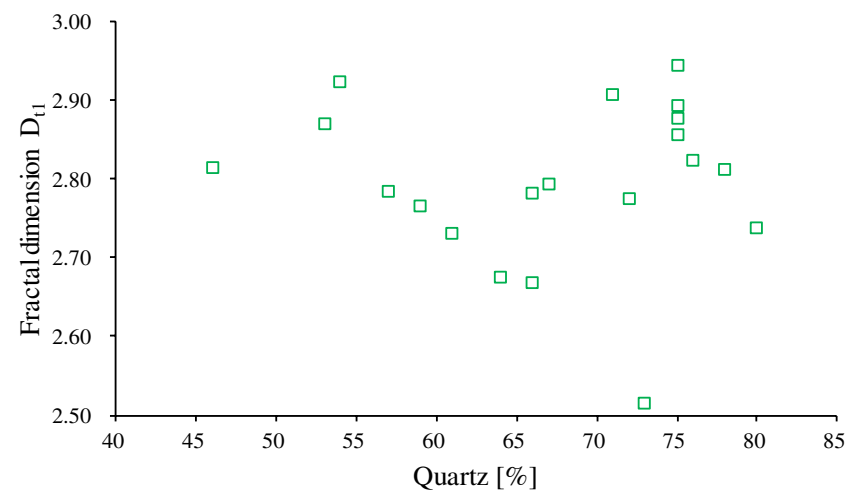

(g)

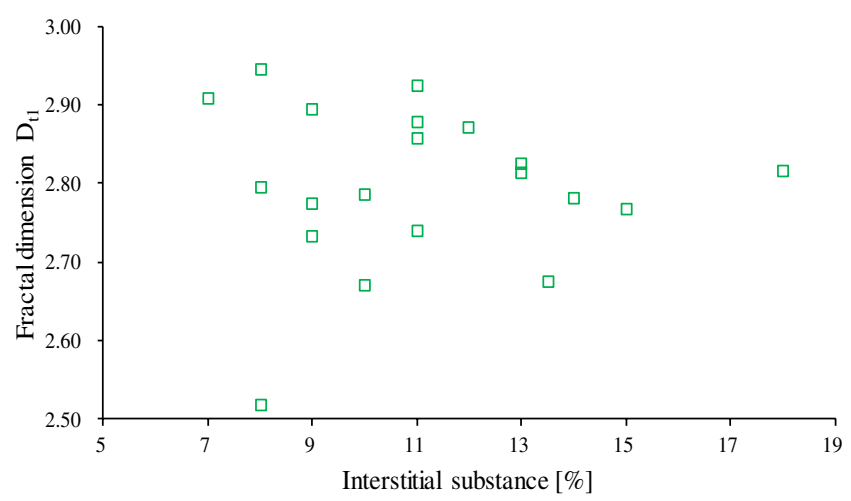

(i)

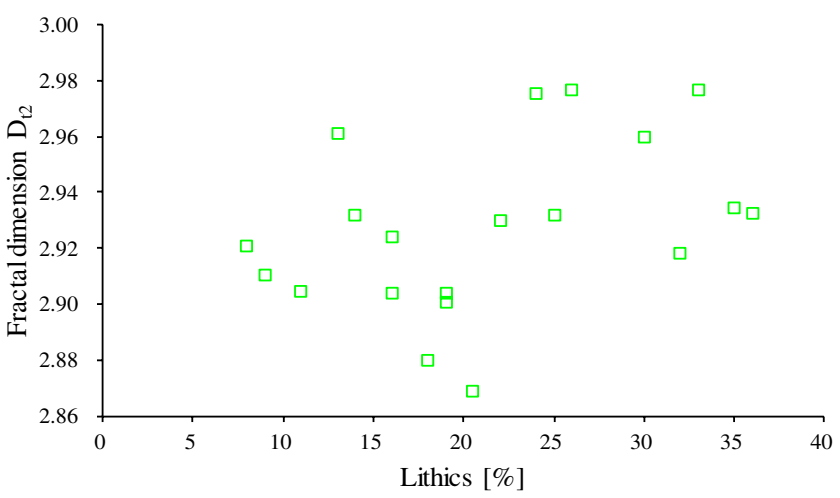

(k)

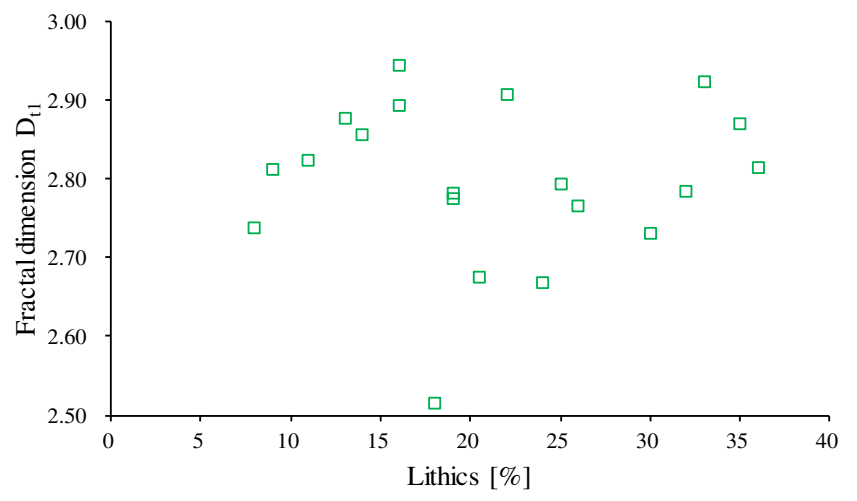

(h)

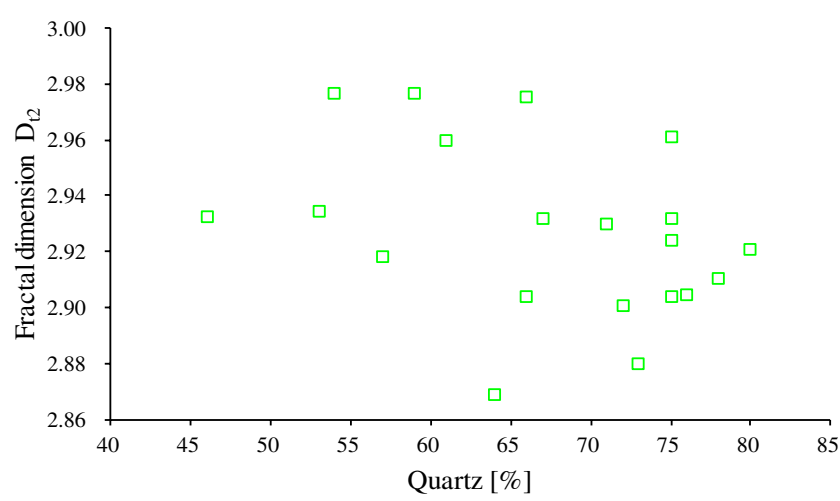

$(\mathbf{j})$



(1)

Fig. 8 (Continued)

\subsection{Effects of Mineral Compositions on Pore-Throat Structures}

Fractal dimensions embody the geometrical structural heterogeneity and irregularity of solids. $\stackrel{47}{4}$ Apparently, the pore-throat structure of the sandstone from the Shihezi Formation may have a decisive control over the rock's fractal dimension. Moreover, the mineral composition, discussed in Sec. 4.2, is also likely to influence the fractal dimension through impacting pore throat structures $\frac{48,50}{50}$
Therefore, pore-throat structure parameters and mineral compositions illustrated in Fig. 9 can explain the way rock mineral compositions impact pore-throat structures.

From Figs. 9a 9f, it can be seen that the average pore radius and throat radius both clearly show positive correlations with the quartz content as well as negative correlations with the lithic fragment and interstitial material contents. Sandstone samples with more quartz excel in both the average pore radius and throat radius, which may be attributed 
H. Huang et al.

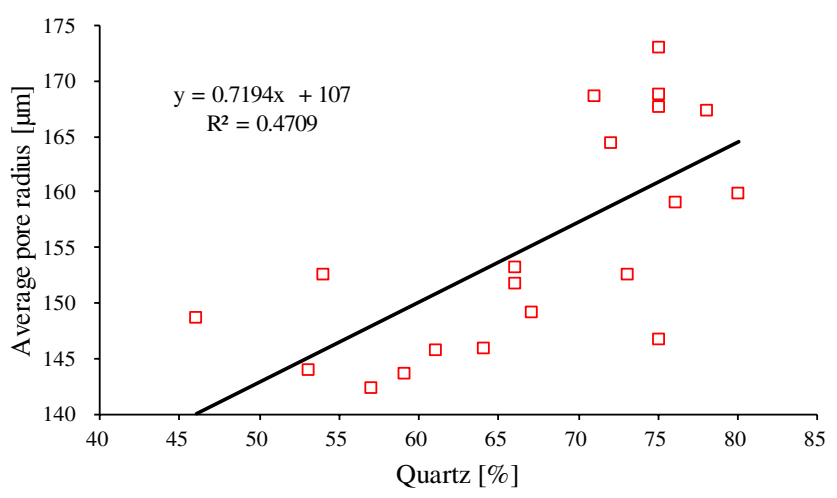

(a)

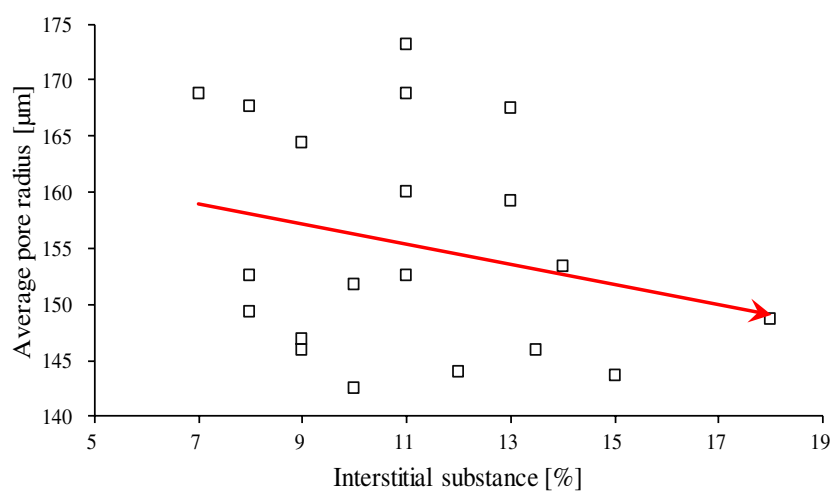

(c)

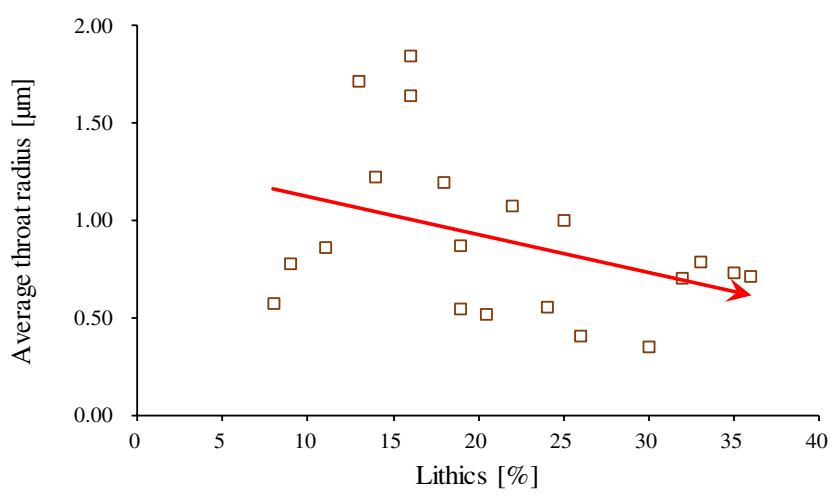

(e)

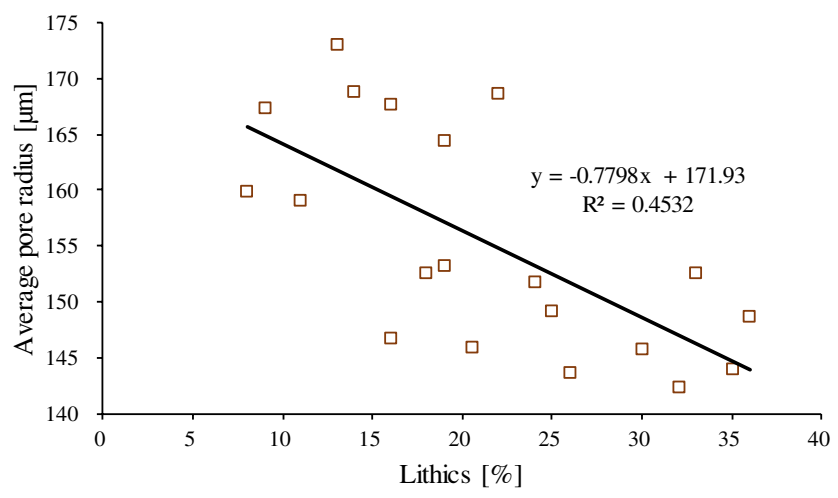

(b)

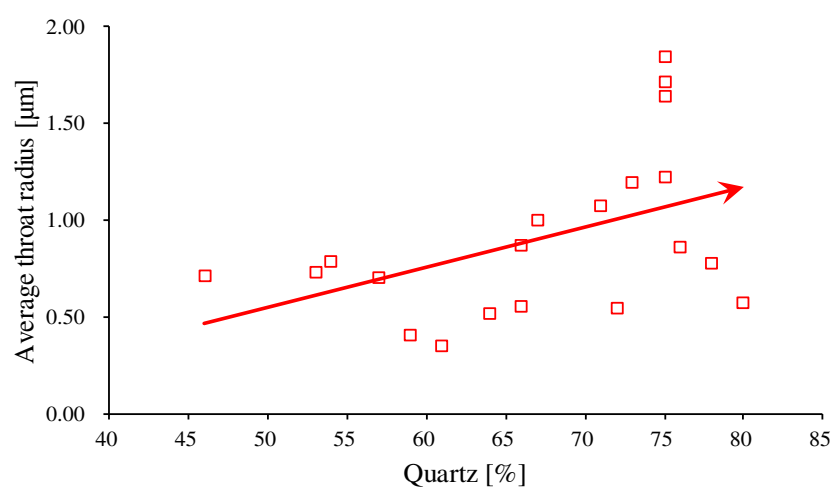

(d)

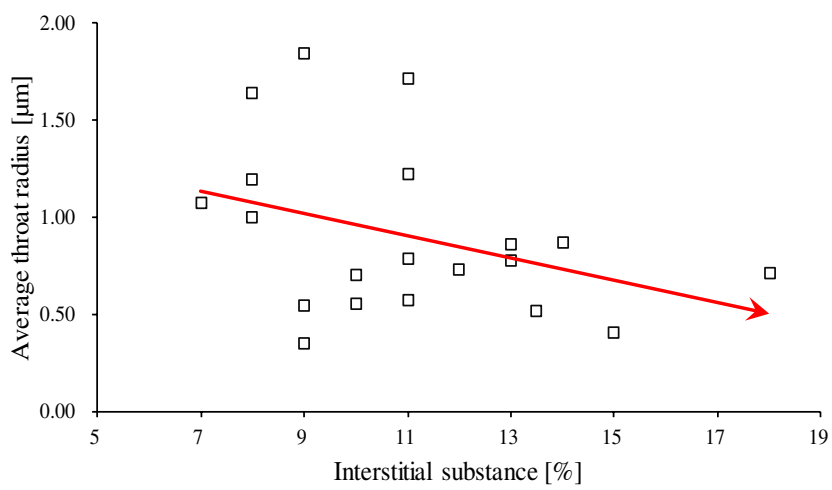

(f)

Fig. 9 Quartz, lithic fragment and interstitial material contents versus average pore radii (a)-(c), average throat radii (d)-(f), pore volumes (g)-(i) and throat volumes (g)-(l).

to the fact that quartz minerals possess more large pores than lithic fragments and interstitial materials.

Both pore volume and throat volume are found to be positively correlated with quartz content (Figs. 9s and 9j), but negatively correlated with lithic fragment and interstitial material contents (Figs. 9h, 91, 9k and 9l). These observations indicate that sandstone samples with higher quartz contents tend to have higher pore volumes and throat volumes, while increases of lithic fragments and interstitial materials reduce them. One potential explanation for this is that quartz can offer more inbuilt pore-throat space, and yet, in most cases, lithic fragments and interstitial materials occupy such room. In addition, these indirectly reflect that mineral compositions are not the reason for the irregular throat dimensions discussed in Secs. 4.1 and 4.2 . 


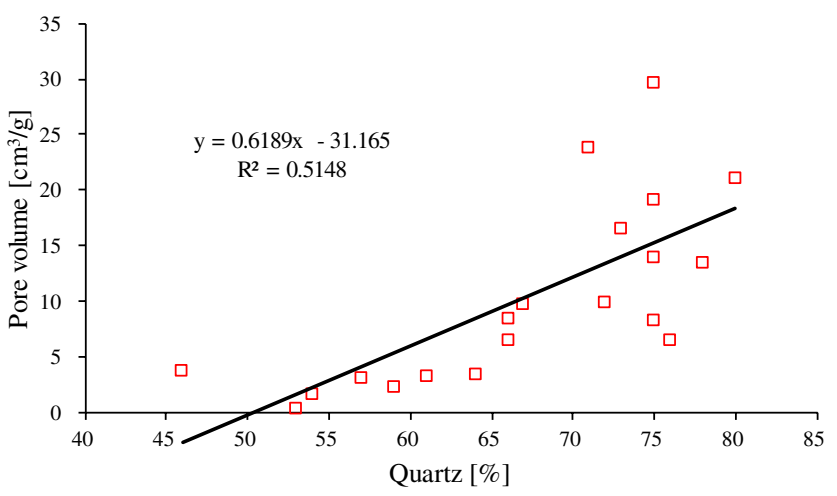

(g)

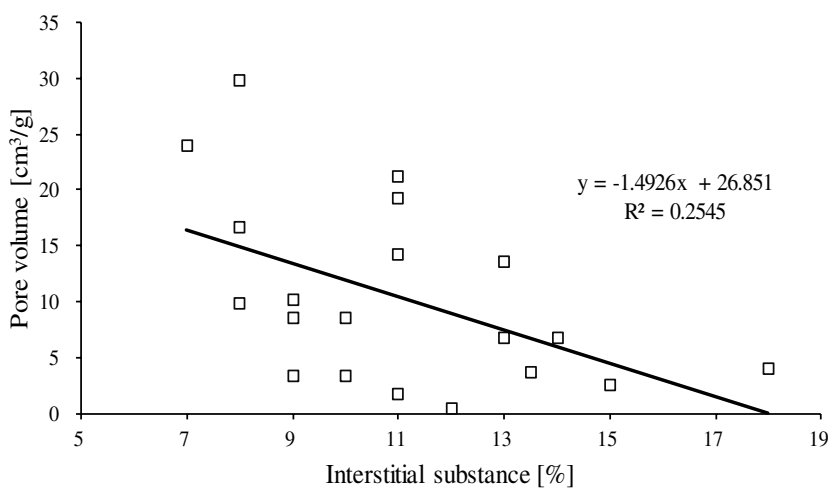

(i)

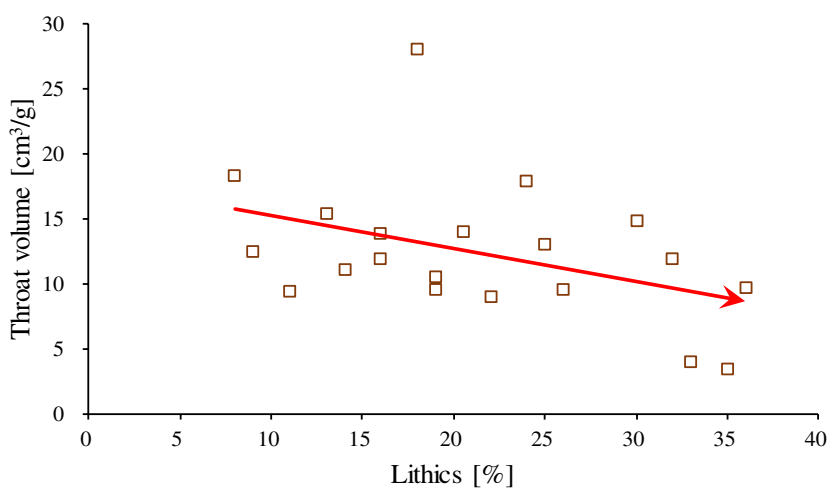

(k)

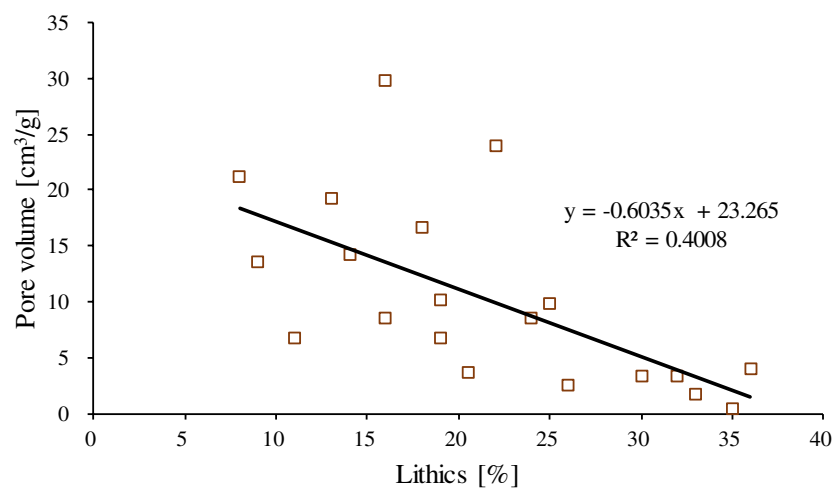

(h)

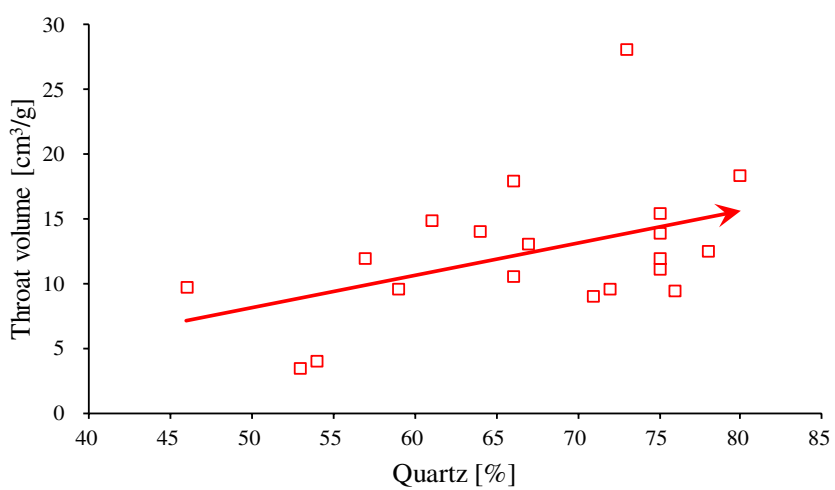

$(\mathbf{j})$

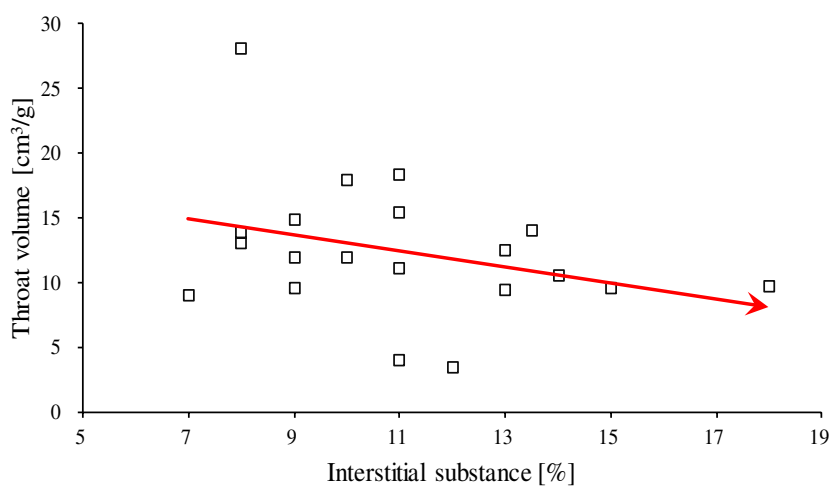

(1)

Fig. 9 (Continued)

Such phenomena should more likely be ascribed to the flake-like and curved shapes of throats.

\subsection{Correlation Between Fractal Dimensions and Relative Permeability}

Discussions focusing on respective effects of fractal features of pores and throats on the effective physical property of tight sands are practically limited, compared with those on fractal dimensions of tight sands 7111 and shales $\frac{[56 / 10}{10}$ Moreover, studies on the respective effects of fractal features of pores and throats on the effective physical property of tight sands are practically limited. In this paper, the relationships between the fractal dimension of pores and throats of tight sandstones from the Shihezi Formation and the effective porosity and effective gas permeability were analyzed. Effective porosity represents the space first occupied by gas that can be really filled with liquid under the gasliquid two-phase condition. It decides that storage 
capacity of gas, and hence higher effective porosity indicates more recoverable reserves. The effective gas permeability is defined as the gas permeability corresponding to the irreducible water saturation, which stands for the maximum gas flow capacity. Higher effective gas permeability generally means more favorable pore-throat structure with respect to reservoir exploitation as well as higher gas production rate.

Figures 10a and 100 show negative correlations between the effective porosity, fractal dimensions $D_{p 2}$ and $D_{p 3}$. Lower fractal dimensions $D_{p 2}$ and $D_{p 3}$ mean simpler pore-throat structure, smoother pore surfaces, less fine pores, more isolated pores and more pores with thin-neck restrictions. In such cases, pores contain lower irreducible water and residual gas, and have larger voids. As for fractal dimensions $D_{t 1}$ and $D_{t 2}$, they are not clearly related to the effective porosity. As fractal dimensions $D_{t 1}$ and $D_{t 2}$ grow, the throat structure is increasingly complex and aggravated tortuosity hinders fluid flow, and yet no notable variation regularity regarding the effective porosity has been



(a)

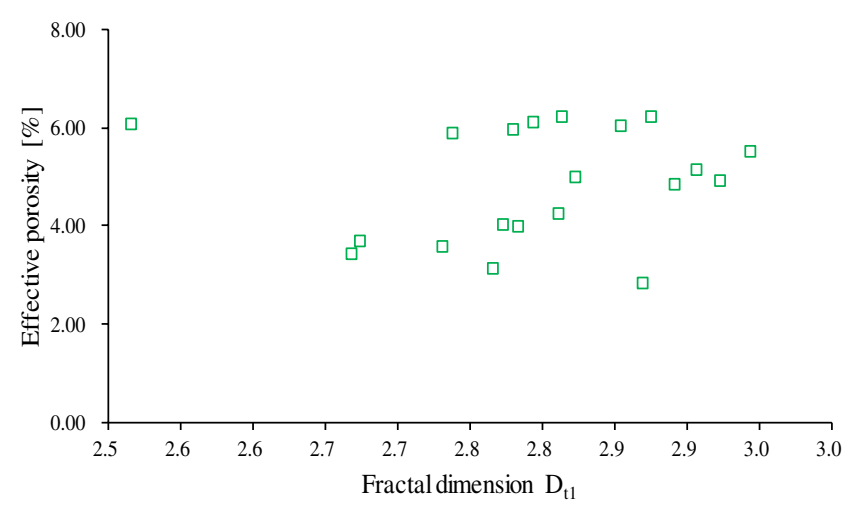

(c) found. A possible cause that may be responsible for this is that sandstones with higher throat fractal dimensions, encounter more difficulty in the transformation from the irreducible water saturation state to the residual gas saturation state. However, such increased throat fractal dimensions have limited effects upon the total recoverable gas volume. To sum up, higher fractal dimensions $D_{p 2}$ and $D_{p 3}$ expand the gas volume in sandstones that can be replaced by liquid and thus promote the recoverable initial gas in place. On the basis of fractal dimensions $D_{p 2}$ and $D_{p 3}$, one can well evaluate the effective gas initially in place of tight sands.

It should also be noted that the effective gas permeability has relatively high negative correlations with fractal dimensions $D_{p 3}$ and $D_{t 2}$, and no clear relationships with fractal dimensions $D_{p 2}$ and $D_{t 1}$. This indicates the determinant influence of structural complexity of large pores and throats on the effective gas permeability. Moreover, fluids possibly have to go through a series of alternating pores and throats, as they flow through the complex porous media in the natural world. Under

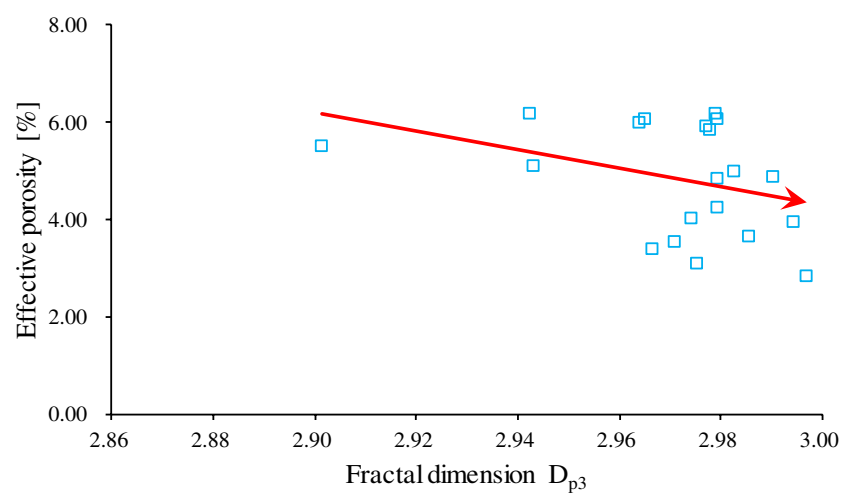

(b)

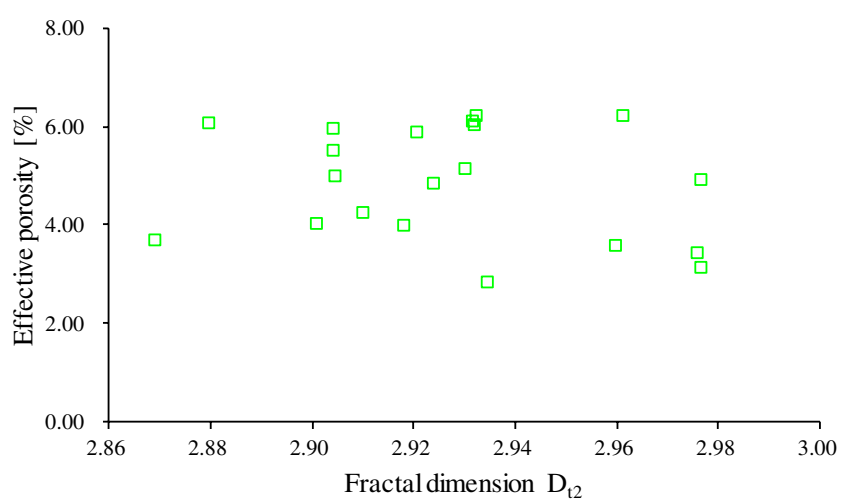

(d)

Fig. 10 Effective porosity and gas permeability versus Fractal dimension $D_{p 2}(\mathbf{a})$ and (e), fractal dimension $D_{p 3}(\mathbf{b})$ and (f), fractal dimensions $D_{t 1}(\mathbf{c})$ and $(\mathbf{g})$ and $D_{t 2}(\mathbf{d})$ and (h). 


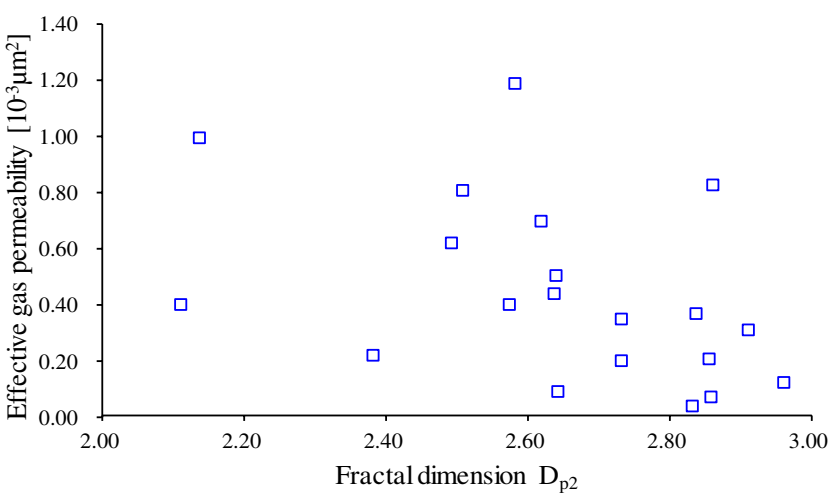

(e)



(g)

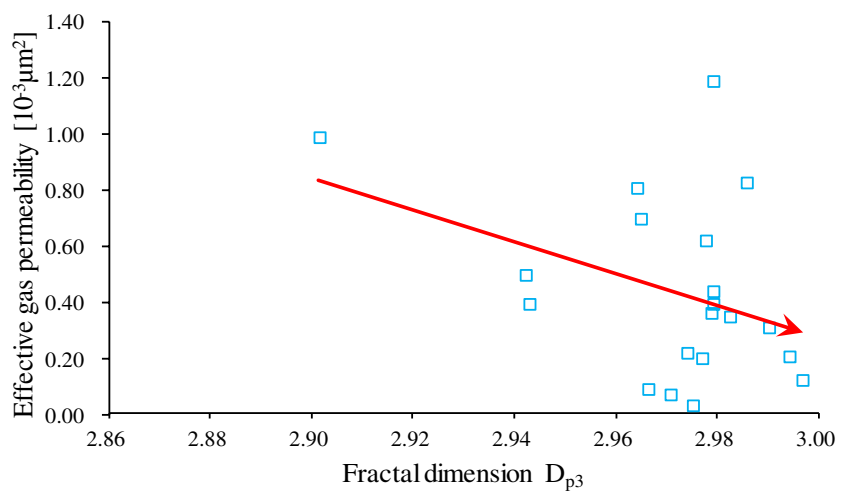

(f)

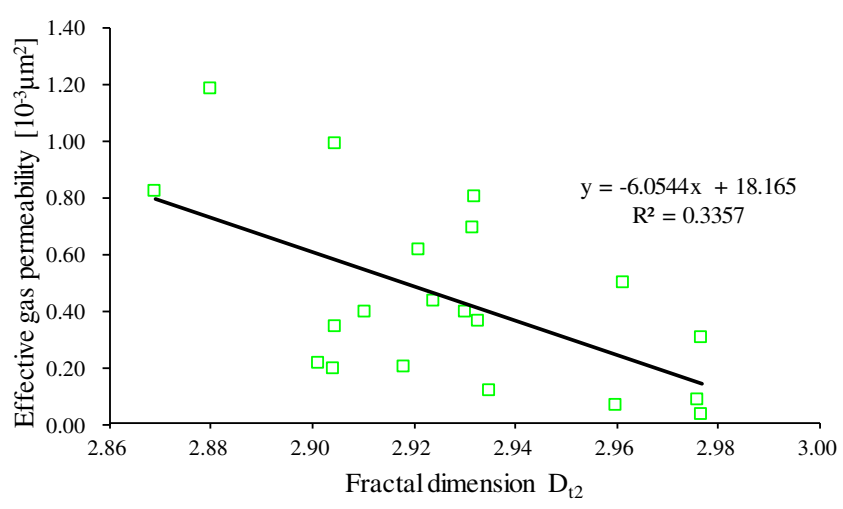

(h)

Fig. 10 (Continued)

such circumstances, the effective gas permeability is under the joint effects of homogeneity of pores and throats. The irrelevance between the structural complexity of small pores and throats and the effective gas permeability might be attributable to the fact that irreducible water tends to accumulate in fine pores and throats, of which the contribution to the effective gas permeability is restrained. In one word, lower fractal dimensions $D_{p 3}$ and $D_{t 2}$ mean easier flow of gas inside the sandstone, which is favorable for the exploitation of tight gas in sandstones. Given the development of the tight gas sandstone reservoir in the Shihezi Formation of the Sulige Gas Field, fractal dimensions are of vital importance.

\section{CONCLUSIONS}

On the basis of constant-rate mercury injection data, this paper applied the fractal theory to the exploration of the fractal feature of the tight gas sandstone. The study target was the Shihezi Formation of the Sulige Gas Field in the Ordos Basin, China. Correlations between pore-throat structures, mineral compositions and fractal dimensions were analyzed. Furthermore, this paper discussed the effects of fractal dimensions on the effective physical property of tight gas sandstones, with reference to the physical significance of fractal dimensions. Conclusions are listed below:

(1) The fractal dimensions of tight gas sandstone samples from the Shihezi Formation, based on constant-rate mercury injection data, are naturally segmented with respect to pore and throat radii. For pores, fractal dimensions are divided into three ranges, of which the latter two ranges are acknowledged as being significant. Fractal dimension $D_{p 2}$ ranges from 2.1098 to 2.9116 , while fractal dimension $D_{p 3}, 2.9423 \sim 2.9900$. In cases of throats, the fractal dimension is divided into two ranges, namely fractal dimension $D_{t 1}$ of $2.5160-2.9235$ and fractal dimension $D_{t 2}$ of $2.8690-2.9767$.

(2) Relatively notable negative correlations between fractal dimensions $D_{p 2}$ and $D_{p 3}$ and the average pore radius as well as those between 
fractal dimensions $D_{p 2}$ and $D_{p 3}$ and pore volume are found. Lower fractal dimensions $D_{p 2}$ and $D_{p 3}$ promote the gas-liquid exchange. Correlations between fractal dimensions $D_{t 1}$ and $D_{t 2}$ and the average throat radius as well as those between fractal dimensions $D_{t 1}$ and $D_{t 2}$ and the throat volume are relatively vague, which might be due to the flake-like and curved shapes of throats.

(3) Higher quartz contents have more positive effects on the average pore radius, average throat radius, pore volume and throat volume. In contrast, lithic fragments and interstitial materials negatively impact the above four parameters. Effects of different mineral compositions on pore-throat structures vary, and this leads to varied fractal dimensions $D_{p 2}, D_{p 3}, D_{t 1}$ and $D_{t 2}$.

(4) Tight gas sandstones with smaller fractal dimensions $D_{p 2}$ and $D_{p 3}$ have larger gas volumes that can be replaced by the liquid phase, which suggests more homogenous and smoother pore surfaces, less irreducible water and residual gas, and hence more voids. This can improve the recoverable gas initially in place. Moreover, for tight gas sandstones with lower fractal dimensions $D_{p 3}$ and $D_{t 2}$, gas can flow more easily through them. This indicates that large pores and throats are characterized by high selfsimilarity, while smaller pores and throats have smoother surfaces. Thus, the resistance that fluids encounter during flowing through the network of smaller alternating pores and throats is lower, which favors the exploitation of tight gas in sandstones.

\section{ACKNOWLEDGMENTS}

This work was supported by the National Science and Technology Major Project (No. 2016ZX05034001) and the National Natural Science Foundation of China (No. 41472112). The authors sincerely thank the PetroChina Changqing Oilfield Company for providing the drill cores used in this study.

\section{REFERENCES}

1. C. Zou, Unconventional Petroleum Geology (Geological Publishing House, 2013), pp. 41-44.

2. W. Dou, The origin of formation water and the regularity of gas and water distribution for the Sulige gas field, Ordos Basin, Acta Petrol. Sin. 31(5) (2010) 767-773.
3. S. A. Holditch, Tight gas sands, J. Pet. Technol. 58(6) (2006) 86-93.

4. K. E. Higgs et al., Diagenesis, porosity evolution, and petroleum emplacement in tight gas reservoirs, Taranaki basin, New Zealand, J. Sediment Res. 77 (2007) 1003-1025.

5. N. Zhang et al., Pore structure characteristics and permeability of deep sedimentary rocks determined by mercury intrusion porosimetry, J. Earth Sci. 27(4) (2016) 670-676.

6. G. Sheng et al., Application of fractal geometry in evaluation of effective stimulated reservoir volume in shale gas reservoirs, Fractals 25(4) (2017) 1740007.

7. W. Huang et al., Reservoir spaces in tight sandstones: Classification, fractal characters, and heterogeneity, J. Nat. Gas Sci. Eng. 46 (2017) 80-92.

8. W. Wei et al., A numerical study on fractal dimensions of current streamlines in two-dimensional and three-dimensional pore fractal models of porous media, Fractals 21(1) (2015) 1540012.

9. F. Yang, Z. Ning and H. Liu, Fractal characteristics of shales from a shale gas reservoir in the Sichuan Basin, China, Fuel 115(1) (2014) 378-384.

10. W. Ji et al., Fractal characteristics of nano-pores in the Lower Silurian Longmaxi shales from the Upper Yangtze platform, South China, Mar. Pet. Geol. 78 (2016) 88-98.

11. P. Li et al., Pore throat structure and fractal characteristics of tight oil sandstone: A case study in the Ordos Basin, China, J. Nat. Gas Sci. Eng. 149 (2016) 665-674.

12. B. D. Bak, Percolation: An invasion percolation model for mercury porosimetry, Fluct. Noise Lett. 16(1) (2017) 1750008.

13. R. G. Loucks et al., Morphology, genesis, and distribution of nanometer scale pores in siliceous mudstones of the Mississippian Barnett Shale, J. Sediment. Res. 79 (2009) 848-861.

14. L. M. Keller et al., 3D geometry and topology of pore pathways in Opalinus 8 clay: Implications for mass transport, Appl. Clay Sci. 52 (2011) 85-95.

15. G. Chalmers, R. Bustin and I. Power, Characterization of gas shale pore systems by porosimetry, pycnometry, surface area, and field emission scanning electron microscopy transmission electron microscopy image analyses: Examples from the Barnett, Woodford, Haynesville, Marcellus, and Doig units, AAPG Bull. 96(6) (2012) 1099-1119.

16. X. Tang et al., A dual-site Langmuir equation for accurate estimation of high pressure deep shale gas resources, Fuel 185 (2016) 10-17.

17. X. Tang et al., Heterogeneous nanoporosity of the Silurian Longmaxi formation shale gas reservoir in the Sichuan Basin using the QEMSCAN, FIB-SEM, and nano-CT methods, Mar. Pet. Geol. 78 (2016) 99-109. 
18. T. Li et al., Effect of pore structure on shale oil accumulation in the lower third member of the Shahejie formation, Zhanhua Sag, eastern China: Evidence from gas adsorption and nuclear magnetic resonance, Mar. Pet. Geol. 88 (2017) 932-949.

19. D. J. K. Ross and R. M. Bustin, The importance of shale composition and pore structure upon gas storage potential of shale gas reservoirs, Mar. Pet. Geol. 26(6) (2009) 916-927.

20. R. Slatt and R. O'Brien, Pore types in the Barnett and Woodford gas shales: Contribution to understanding gas storage and migration pathways in fine-grained rocks, AAPG Bull. 95(12) (2011) 2017 2030 .

21. M. Meng et al., Monitor the process of shale spontaneous imbibition in co-current and counter-current displacing gas by using low field nuclear magnetic resonance method, J. Nat. Gas Sci. Eng. 27 (2015) $336-345$.

22. L. Chen et al., Effect of lithofacies on gas storage capacity of marine and continental shales in the sichuan basin, China, J. Nat. Gas Sci. Eng. 36 (2016) 773-785.

23. F. Xiong et al., The shale gas sorption capacity of transitional shales in the Ordos Basin, NW China, Fuel 208 (2017) 236-246.

24. U. Kuila and M. Prasad, Surface area and poresize distribution in clays and shales, in $S P E$ Annual Technical Conf. and Exhibition (Society of Petroleum Engineers, 2011), pp. 1-13.

25. H. Zhao et al., Petrophysical characterization of tight oil reservoirs using pressure-controlled porosimetry combined with rate-controlled porosimetry, Fuel 154 (2015) 233-242.

26. W. Ji et al., Geological controls and estimation algorithms of lacustrine shale gas adsorption capacity: A case study of the Triassic strata in the southeastern Ordos Basin, China, Int. J. Coal Geol. 134-135(1) (2014) 61-73.

27. C. Jia et al., Architecture and quantitative assessment of channeled clastic deposits, Shihezi sandstone (Lower Permian), Ordos Basin, China, J. Nat. Gas Geosci. 2(1) (2017) 11-20.

28. H. Huang et al., Effects of pore-throat structure on gas permeability in the tight sandstone reservoirs of the Upper Triassic Yanchang formation in the Western Ordos Basin, China, J. Pet. Sci. Eng. 162 (2018) 602-616.

29. L. Chen et al., Pore structure characterization for organic-rich Lower Silurian shale in the Upper Yangtze Platform, South China: A possible mechanism for pore development, J. Nat. Gas Sci. Eng. 46 (2017) 1-15.

30. W. R. Purcell, Capillary pressures-their measurement using mercury and the calculation of permeability therefrom, J. Pet. Technol. 1(2) (1949) 39-48.

31. N. R. Morrow, Physics and thermodynamics of capillary action in porous media, Ind. Eng. Chem. 62(6) (1970) 32-56.

32. H. Yuan and B. F. Swanson, Resolving pore-space characteristics by rate-controlled porosimetry, SPE Form. Eval. 4(1) (1989) 17-24.

33. N. C. Wardlaw, Quantitative determination of pore structure and application to fluid displacement in reservoir rocks, in North Sea Oil and Gas Reservoirs - II (Springer, Netherlands, 1990), pp. 299243.

34. S. M. Hassanizadeh, M. A. Celia and H. K. Dahle, Dynamic effect in the capillary pressure-saturation relationship and its impacts on unsaturated flow, Vadose Zone J. 1(1) (2002) 38-57.

35. Y. Zhou et al., Controls on reservoir heterogeneity of tight sand oil reservoirs in Upper Triassic Yanchang Formation in Longdong Area, southwest Ordos Basin, China: Implications for reservoir quality prediction and oil accumulation, Mar. Pet. Geol. 78 (2016) 110-135.

36. B. B. Mandelbrot, D. E. Passoja and A. J. Paullay, Fractal character of fracture surfaces of metals, Nature 308 (1984) 721-722.

37. A. Roy and E. Perfect, Lacunarity analyses of multifractal and natural grayscale patterns, Fractals $22(3)$ (2014) 468-476.

38. X. Liu, J. Xiong and L. Liang, Investigation of pore structure and fractal characteristics of organic-rich Yanchang formation shale in central China by nitrogen adsorption/desorption analysis, J. Nat. Gas Sci. Eng. 22(7) (2015) 62-72.

39. Y. Xia et al., A new method for calculating fractal dimensions of porous media based on pore size distribution, Fractals 26(1) (2018) 1850006.

40. P. Xu et al., A fractal network model for fractured porous media, Fractals 24(2) (2016) 1650018.

41. S. Volland and J. H. Kruhl, Anisotropy quantification: The application of fractal geometry methods on tectonic fracture patterns of a Hercynian fault zone in NW Sardinia, J. Struct. Geol. 26(8) (2004) 1499-1510.

42. P. Zhao et al., Investigation on the pore structure and multifractal characteristics of tight oil reservoirs using NMR measurements: Permian Lucaogou formation in Jimusaer Sag, Junggar Basin, Mar. Pet. Geol. 86 (2017) 1067-1081.

43. B. Yu, M. Zou and Y. Feng, Permeability of fractal porous media by Monte Carlo simulations, Int. J. Heat Mass Transfer 48(13) (2005) 2787-2794.

44. B. Yu, J. Cai and M. Zou, On the physical properties of apparent two-phase fractal porous media, Vadose Zone J. 8(1) (2009) 177-186. 


\section{H. Huang et al.}

45. J. Cai et al., Fractal characterization of spontaneous co-current imbibition in porous media, Energy Fuels 24(3) (2010) 1860-1867.

46. Z. Yuan and P. Liu, A new capillary pressure model using fractal geometry for coal porous media, Sci. Technol. Eng. 15(9) (2015) 63-67.

47. P. Pfeifer and D. Avnir, Chemistry nonintegral dimensions between two and three, J. Chem. Phys. 79 (1983) 3369-3558.

48. L. Chen et al., Quantitative characterization of micropore structure for organic-rich Lower Silurian shale in the Upper Yangtze platform, South
China: Implications for shale gas adsorption capacity, Adv. Geo-Energ. Res. 1(2) (2017) 112-123.

49. P. Wang et al., Lithofacies classification and its effect on pore structure of the Cambrian marine shale in the Upper Yangtze Platform, South China: Evidence from FE-SEM and gas adsorption analysis, J. Nat. Gas Sci. Eng. 156 (2017) 307-321.

50. S. Zhang et al., Paleoenvironmental conditions, organic matter accumulation, and unconventional hydrocarbon potential for the Permian Lucaogou formation organic-rich rocks in Santanghu Basin, NW China, Int. J. Coal Geol. 185 (2018) 44-60. 